\title{
MERCADO ÚNICO DIGITAL: MEDIDAS CONTRA EL BLOQUEO GEOGRÁFICO INJUSTIFICADO, CONTRATOS DE CONSUMO CONCLUIDOS POR VÍA ELECTRÓNICA Y NORMAS DE DERECHO INTERNACIONAL PRIVADO*
}

\author{
EU DIGITAL SINGLE MARKET: MEASURES AGAINST \\ UNJUSTIFIED GEO-BLOCKING, ELECTRONIC CONSUMER \\ CONTRACTS AND THE CONFLICT OF LAWS
}

\author{
RAÚl LAFUENTE SÁNCHEZ \\ Profesor Titular acreditado de Derecho internacional privado \\ Universidad de Alicante \\ ORCID ID: 0000-0002-0348-2530
}

Recibido: 29.05.2019 / Aceptado: 13.06.2019

DOI: https://doi.org/10.20318/cdt.2019.4953

\begin{abstract}
Resumen: El Reglamento sobre bloqueo geográfico injustificado tiene como finalidad eliminar la discriminación directa e indirecta basada en la nacionalidad, el lugar de residencia o el lugar de establecimiento de los clientes. Para alcanzar este objetivo, prohíbe a los comerciantes el uso de medidas tecnológicas o de otro tipo con el fin de bloquear o limitar el acceso de los clientes a sus interfaces en línea. Por otra parte, dispone que del cumplimiento del Reglamento no se derivará que el comerciante dirige sus actividades al domicilio o residencia habitual del consumidor en el sentido de lo dispuesto en los Reglamentos Bruselas I bis y Roma I. De esta declaración puede derivarse una posible interferencia con los criterios ya definidos en la jurisprudencia del Tribunal de Justicia a la hora de delimitar cuando un comerciante ha dirigido sus actividades al Estado miembro del domicilio o residencia habitual del consumidor. En el presente trabajo estudio y analizo esta cuestión, así como sus posibles consecuencias en los contratos de consumo celebrados por vía electrónica.
\end{abstract}

Palabras clave: mercado único digital, bloqueo geográfico injustificado, reglamento (UE) 2018/302, derecho internacional privado, contratos de consumo electrónicos, concepto de "actividades dirigidas".

\begin{abstract}
The unjustified geo-blocking Regulation aims to eliminate direct and indirect discrimination based on customers' nationality, place of residence or place of establishment. In order to achieve this goal, prohibits to traders the use of technological measures or otherwise, to block or limit a customer's access to their online interfaces for reasons related to the customer's nationality, place of residence or place of establishment. Moreover, the Regulation provides that compliance with its rules shall not be construed as implying that a trader directs activities to the Member State of the consumer's habitual residence or domicile within the meaning of Brussels I Regulation and Rome I Regulation. This statement raises a possible interference with the criteria identified in the European Court of Justice case law, in order to delimit when a trader has directed his activities to the Member State of the consumer's
\end{abstract}

* Trabajo elaborado en el marco del Proyecto de investigación DER 2017-84748-R (PROY I+D+i del Ministerio de Economía, Industria y Competitividad, MINECO, 2018-2021. DSM-CONSUMER) titulado Mercado único digital europeo y protección de los consumidores: perfilando los derechos de las partes en contratos de suministro de contenidos digitales. 
habitual residence or domicile. In this paper I analyze the aforementioned issue and its consequences for the electronic consumer contracts.

Keywords: EU digital single market, unjustified geo-blocking, regulation (EU) 2018/302, conflict of laws, electronic consumer contracts, concept of "directing activities".

Sumario: I. Introducción. II. El Reglamento sobre bloqueo geográfico injustificado. 1. Planteamiento. 2. Objetivos y ámbito de aplicación del Reglamento. 3. Obligaciones que impone el Reglamento a los comerciantes. A) Permitir el acceso a sus interfaces en línea. B) No aplicar condiciones de acceso diferentes a sus productos y servicios. a) Adquisición de productos con entrega física en la zona determinada por el comerciante. b) Servicios que se prestan por vía electrónica y no requieren entrega física. c) Servicios que no se prestan por vía electrónica y que el cliente recibe en un lugar físico. C) No aplicar condiciones discriminatorias por motivos relacionados con el pago. D) No permitir acuerdos sobre ventas pasivas que infrinjan la prohibición del bloqueo geográfico. 4. Interacción del Reglamento con las normas de Derecho internacional privado. III. El concepto de "actividades dirigidas al Estado miembro del domicilio o residencia habitual del consumidor". 1. Planteamiento. 2. Doctrina del TJUE en esta materia. A) Las "actividades dirigidas a un Estado miembro" como criterio de atribución de competencia judicial internacional. B) Indicios objetivos identificados por el TJUE para considerar que el comerciante ha dirigido sus actividades al Estado miembro del domicilio del consumidor. a) Asunto Pammer y Alpenhof. b) Asunto Mühlleitner. c) Asunto Emrek. d) Asunto Kampik. IV. Análisis de los indicios identificados por el TJUE en su jurisprudencia a la luz del Reglamento sobre bloqueo geográfico injustificado. 1. El acceso a la interfaz del comerciante desde el Estado del domicilio del consumidor no constituye un indicio de que haya dirigido su actividad a ese país. 2. Coexistencia entre el acceso a la interfaz y la libertad del comerciante para excluir de la contratación a los clientes domiciliados en un Estado miembro. A) Carácter distintivo de las páginas web interactivas y pasivas. B) Distinción entre consumidores activos y pasivos. 3. Relevancia del lugar de entrega de los productos o servicios del comerciante para determinar si ha dirigido sus actividades al Estado del domicilio del consumidor. 4. El cumplimiento de los requisitos legales nacionales no contractuales del Estado miembro del cliente y su incidencia en el criterio de las "actividades dirigidas". 5. ¿Cómo ha de interpretarse el hecho de que del Reglamento no conlleva para el comerciante ningún coste adicional asociado a la competencia judicial o a diferencias en el derecho aplicable?. V. Consideraciones finales.

\section{Introducción}

1. En el año 2015, en el marco de la Estrategia para el Mercado Único Digital ${ }^{1}$ y la Estrategia del Mercado Único², la Comisión Europea presentó sendas propuestas de Directiva del Parlamento Europeo y del Consejo; la primera relativa a determinados aspectos de los contratos de suministro de contenidos digitales $^{3}$ y, la segunda, relativa a determinados aspectos de los contratos de compraventa en línea y otras ventas a distancia de bienes y su Propuesta modificada ${ }^{4}$. Recientemente, acaban de publicarse las

${ }^{1}$ Comunicación de la Comisión al Parlamento Europeo, al Consejo, al Comité Económico y Social Europeo y al Comité de las Regiones, Una Estrategia para el Mercado Único Digital de Europa, COM (2015) 192 final, de 6.05.2015.

${ }^{2}$ Comunicación de la Comisión al Parlamento Europeo, al Consejo, al Comité Económico y Social Europeo y al Comité de las Regiones, Mejorar el mercado único: más oportunidades para los ciudadanos y las empresas, COM (2015) 0550 final, de 28.10.2015.

${ }^{3}$ Propuesta de Directiva del Parlamento Europeo y del Consejo relativa a determinados aspectos de los contratos de suministro de contenidos digitales, COM (2015) 0634 final de 9.12.2015 (en adelante, Propuesta de Directiva sobre contenidos digitales).

${ }^{4}$ Propuesta de Directiva del Parlamento Europeo y del Consejo relativa a determinados aspectos de los contratos de compraventa en línea y otras ventas a distancia de bienes, COM (2015) 635 final, de 9.12.2015. Propuesta modificada de Directiva del Parlamento Europeo y del Consejo relativa a determinados aspectos de los contratos de compraventa de bienes, por la que se modifican el Reglamento (CE) no 2006/2004 del Parlamento Europeo y del Consejo y la Directiva 2009/22/CE del Parlamento Europeo y del Consejo y se deroga la Directiva 1999/44/CE del Parlamento Europeo y del Consejo, COM (2017) 637 final, de 31.10.2017 (en adelante, Propuesta de Directiva sobre contratos de compraventa de bienes). Esta Directiva abarca un ámbito de aplicación más amplio que la Directiva 1999/44/CE del Parlamento Europeo y del Consejo, de 25 de mayo de 1999, sobre determinados aspectos de la venta y las garantías de los bienes de consumo (DOUE L 171 de 07.07.1999) a la que sustituirá, regulando tanto las ventas a distancia cuanto las presenciales. 
mencionadas normas que tienen como objetivo armonizar la legislación de protección de los consumidores en los Estados miembros en los ámbitos que regulan. Se trata de la Directiva 2019/770, relativa a determinados aspectos de los contratos de suministro de contenidos y servicios digitales ${ }^{5}$, y la Directiva $2019 / 771$, relativa a determinados aspectos de los contratos de compraventa de bienes ${ }^{6}$.

2. Como elemento común, ambos textos disponen que serán compatibles con las normas existentes en la Unión Europea sobre la competencia judicial internacional y la legislación aplicable en el Mercado Único Digital, que establecen un marco jurídico claro para comprar y vender en un mercado digital europeo teniendo en cuenta los intereses tanto de los consumidores cuanto de las empresas. En consecuencia, que no se requiere ningún cambio y que la entrada en vigor de las mismas no debe obstaculizar la aplicación de las normas de derecho internacional privado actualmente en vigor?

Por consiguiente, a los contratos de suministro de contenidos digitales y de compraventa de bienes les serán de aplicación las mismas normas para determinar la competencia judicial internacional y la ley aplicable. Además, al tratarse de dos Directivas de armonización plena, con su aplicación se pretende garantizar un elevado nivel de protección de los consumidores y contribuir a la creación de un marco jurídico que beneficie el buen funcionamiento del mercado interior. Esto implica que los Estados no podrán adoptar o mantener leyes que no alcancen o que vayan más allá de los requisitos regulados en las citadas Directivas ${ }^{8}$, eliminando, así, los problemas que plantea la disparidad legislativa actualmente existente y el riesgo de forum shopping, con el fin de buscar la aplicación de la ley más favorable a los intereses del consumidor, que provoca la ausencia de unificacion de estas normas.

3. Posteriormente, en el año 2016, la Comisión presentó una propuesta9que dio lugar al Reglamento sobre medidas destinadas a impedir el bloqueo geográfico injustificado y otras formas de discriminación por razón de la nacionalidad, del lugar de residencia o del lugar de establecimiento de los clientes en el mercado interior ${ }^{10}$, y que merece especial atención por lo que respecta a los contratos de suministro de contenidos digitales concluidos con consumidores.

En la misma línea que las dos propuestas de Directiva antes mencionadas, el Reglamento reconoce implícitamente que el marco jurídico existente en materia de derecho internacional privado debe ser suficiente, y sus disposiciones han de entenderse sin perjuicio del Derecho de la Unión relativo a la cooperación judicial en materia civil y, en particular, de las disposiciones sobre la ley aplicable a las obligaciones contractuales y sobre la competencia judicial internacional ${ }^{11}$.

${ }^{5}$ Directiva (UE) 2019/770 del Parlamento Europeo y del Consejo, de 20 de mayo de 2019, relativa a determinados aspectos de los contratos de suministro de contenidos y servicios digitales (Texto pertinente a efectos del EEE) (DOUE L 136, 22.5.2019).

${ }^{6}$ Directiva (UE) 2019/771 del Parlamento Europeo y del Consejo, de 20 de mayo de 2019, relativa a determinados aspectos de los contratos de compraventa de bienes, por la que se modifican el Reglamento (CE) n. ${ }^{\circ}$ 2017/2394 y la Directiva 2009/22/ CE y se deroga la Directiva 1999/44/CE (Texto pertinente a efectos del EEE) (DOUE L 136, 22.5.2019).

7 Vid. los Considerandos 80 de la Directiva sobre contratos de suministro de contenidos y servicios digitales y 65 de la Directiva sobre contratos de compraventa. En ambos casos señalan que sus disposiciones deben aplicarse sin perjuicio de la aplicación de las normas de Derecho internacional privado.

${ }^{8}$ El artículo 4 de la Directiva sobre contratos de suministro de contenidos digitales dispone: Los Estados miembros no podrán mantener o introducir disposiciones contrarias a las establecidas en la presente Directiva, en particular disposiciones más o menos estrictas para garantizar un nivel diferente de protección de los consumidores. Prácticamente, la misma redacción que la incluida en el artículo 3 de la Directiva sobre los contratos de compraventa de bienes.

${ }^{9}$ Propuesta de Reglamento del Parlamento Europeo y del Consejo sobre medidas contra el bloqueo geográfico injustificado y otras formas de discriminación por razón de la nacionalidad o del lugar de residencia o de establecimiento de los clientes en el mercado interior y por el que se modifican el Reglamento (CE) no 2006/2004 y la Directiva 2009/22/CE. COM (2016) 289 final, de 25.05.2016, acompañado de los siguientes documentos de trabajo: SWD (2016) 173 final y SWD (2016) 174 final.

${ }^{10}$ Reglamento (UE) 2018/302 del Parlamento Europeo y del Consejo de 28 de febrero de 2018 sobre medidas destinadas a impedir el bloqueo geográfico injustificado y otras formas de discriminación por razón de la nacionalidad, del lugar de residencia o del lugar de establecimiento de los clientes en el mercado interior y por el que se modifican los Reglamentos (CE) $n^{\circ}$ 2006/2004 y (UE) 2017/2394 y la Directiva 2009/22/CE, (DOUE L 60, de 2.03.2018) (en adelante, Reglamento sobre bloqueo geográfico).

${ }^{11}$ Considerando 13 del Reglamento sobre bloqueo geográfico. 
4. Teóricamente, pues, las normas de conflicto existentes en el ámbito de la Unión Europea y, en particular, el Reglamento 1215/2012 del Parlamento Europeo y del Consejo ${ }^{12}$, y el Reglamento $593 / 2008$ del Parlamento Europeo y del Consejo ${ }^{13}$, han de considerarse suficientes a la hora de solventar las cuestiones conflictuales que se planteen como consecuencia de la puesta en marcha del mercado único digital, ya sea para determinar la competencia judicial internacional o la ley aplicable en materia de contratos de suministro de contenidos digitales concluidos con consumnidores ${ }^{14}$.

En este sentido, conviene recordar que el Reglamento Bruselas I bis, como excepción a la regla general del domicilio del demandado y a las competencias especiales en materia contractual ${ }^{15}$, establece un marco favorable al consumidor en los contratos celebrados para un uso que pueda considerarse ajeno a su actividad profesional, y prevé la competencia de los tribunales del domicilio del consumidor de forma voluntaria, cuando la demanda sea interpuesta por el consumidor, y de manera obligatoria cuando la demanda proceda de la otra parte contratante ${ }^{16}$. Para ello, la conditio sine qua non es que "... la otra parte contratante ejerza actividades comerciales o profesionales en el Estado miembro del domicilio del consumidor o, por cualquier medio, dirija tales actividades a dicho estado miembro o a varios Estados miembros, incluido este último, y el contrato esté incluido en el marco de dichas actividades" ${ }^{\prime 17}$.

Por su parte, en el ámbito de la ley aplicable, el Reglamento Roma I dispone que la ley aplicable a los contratos de consumo será la ley del país en que el consumidor tenga su residencia habitual siempre que se cumpla alguna de las condiciones que allí se establecen, a saber: que el profesional "a) ejerza sus actividades comerciales o profesionales en el país donde el consumidor tenga su residencia habitual, $o$ b) por cualquier medio dirija estas actividades a ese país o a distintos países, incluido ese país, y el contrato estuviera comprendido en el ámbito de dichas actividades" ${ }^{\prime \prime}$.

5. El objetivo de estas normas es proteger al consumidor como parte débil en sus relaciones con el empresario que dispone de mayores recursos económicos, teniendo en cuenta que la mayoría de los contratos en los que intervienen consumidores son contratos de adhesión donde no cabe la elección del foro o de la ley aplicable.

Y resulta evidente que ambas disposiciones están pensadas para aplicarse a los contratos de consumo on line pues, aunque en su redacción no se refiere explícitamente a la contratación on line, la condición de que el profesional dirija por cualquier medio su actividad al país en el que el consumidor tenga su residencia habitual resulta muy clarificadora al respecto. Nos encontramos, por tanto, ante el concepto de "actividades dirigidas a un país concreto" o la denominada "International Stream-OfCommerce Rule" que persigue la conquista de ese mercado ${ }^{19}$.

\footnotetext{
${ }^{12}$ Reglamento 1215/2012 del Parlamento Europeo y del Consejo de 12 de diciembre de 2012 relativo a la competencia judicial, el reconocimiento y la ejecución de resoluciones judiciales en materia civil y mercantil (DOUE L 351, de 20.12.2012) (en adelante, Reglamento Bruselas I bis)

${ }^{13}$ Reglamento 593/2008 del Parlamento Europeo y del Consejo de 17 de junio de 2008 sobre la ley aplicable a las obligaciones contractuales (Roma I) (DOUE L 177, de 4.07.2008) (en adelante, Reglamento Roma I).

${ }^{14}$ Considerando 49 de la Propuesta de Directiva sobre contenidos digitales.

${ }^{15}$ Artículos 4 y 7.1 del Reglamento Bruselas I bis.

${ }_{16}$ Ibidem, artículo 18, que dispone: 1. "La acción entablada por un consumidor contra la otra parte contratante podrá interponerse ante los órganos jurisdiccionales del Estado miembro en que esté domiciliada dicha parte o, con independencia del domicilio de la otra parte, ante el órgano jurisdiccional del lugar en que esté domiciliado el consumidor.

2. La acción entablada contra el consumidor por la otra parte contratante solo podrá interponerse ante los órganos jurisdiccionales del Estado miembro en que esté domiciliado el consumidor...."

17 Ibidem, artículo $17.1 \mathrm{c})$.

${ }^{18}$ Artículo 6.1 del Reglamento Roma I.

${ }_{19}$ Respecto a la doctrina del "International Stream of Commerce" o mercado de conquista, sus orígenes en el Derecho internacional privado norteamericano y su delimitación en la jurisprudencia de los tribunales americanos, Vid., mi trabajo, R. LAFUEnTE SÁnChEZ, "El criterio del International Stream-of-Commerce y los foros de competencia en materia de contratos electrónicos celebrados con consumidores, Cuadernos de Derecho Transnacional, vol. 4, nº 2, Octubre 2012, pp. 177-201. Por su parte, A. L. Calvo Caravaca y J. Carrascosa González, (Dirs.), Derecho internacional privado, vol. II, 18 a ed., Comares, Granada, 2018, pp. 1123-1124, distinguen entre la Stream-Of-Commerce Rule, cuando la empresa dirige sus actividades al país del consumidor, y la Doing Business Rule, que implica que la empresa ya opera habitualmente en ese territorio.
} 
6. Precisamente, el Reglamento sobre bloqueo geográfico injustificado incorpora en su texto un apartado cuya interpretación puede resultar algo confusa respecto al concepto de "actividades dirigidas" y el alcance que puede tener tanto desde la perspectiva del comerciante o prestador de servicios cuanto del consumidor en los contratos de suministro de contenidos digitales, especialmente a la luz de lo dispuesto en los Reglamentos Bruselas I bis y Roma I y de la jurisprudencia del TJUE en esta materia, de manera que se pueden plantear algunas cuestiones controvertidas que son objeto de estudio y análisis en el presente trabajo.

\section{El Reglamento sobre bloqueo geográfico injustificado}

\section{Planteamiento}

7. Con el incremento exponencial de las transacciones transfronterizas que se ha venido produciendo de un tiempo a esta parte, propiciado por el uso cada vez mas generalizado de las nuevas tecnologías de la información y, en particular, de internet que ha cambiado la forma en que sus usuarios se conectan y efectuan sus transacciones comerciales, algunos comerciantes y prestadores de servicios han ido adoptando medidas restrictivas que discriminan al consumidor en función de su lugar de residencia o nacionalidad.

Uno de los métodos que han venido utilizando es el bloqueo geográfico con el objetrivo de impedir que sus interfacesen línea puediesen ser accesibles a empresas y consumidores de determinados Estados o zonas geográficas con los que no deseaban contratar. Junto a esta práctica que, de acuerdo con los datos obrantes, resulta ampliamente utilizada en la Unión Europea ${ }^{20}$, existe otra no menos extendida que consiste en redirigir a los usuarios que acceden a una web localizada en un Estado miembro a otra ubicada en el Estado miembro de su residencia habitual.

Sin lugar a dudas, estas actuaciones fragmentan los mercados en función del lugar de residencia de los clientes y pueden representar una barrera al crecimiento y desarrollo del comercio electrónico y, por extensión, del mercado único digital.

8. Estas prácticas tratan de justificarse por las disparidades existentes en las legislaciones nacionales en materias tan sensibles como la fiscal o la protección del consumidor y, por ende, en la incertidumbre e inseguridad jurídica que plantea la posible aplicación de una legislación extranjera cuando se trata de contratos celebrados en el ámbito del $B 2 C^{21}$. Y por ello, los comerciantes, conscientes de que dirigir su actividad a todos los Estados miembros en las mismas condiciones cuando no existe un marco legal uniforme podría perjudicar sus intereses, en determinadas ocasiones aplican condiciones diferentes en sus contratos adaptándolos a cada mercado y excluyendo algunos territorios de su ámbito de actividad.

\section{Objetivos y ámbito de aplicación del Reglamento}

9. Con el objetivo de regular esta práctica, el Parlamento Europeo y el Consejo adoptaron el Reglamento sobre bloqueo geográfico injustificado que es de aplicación desde el 3 de diciembre de 2018. Se trata de un instrumento que forma parte del paquete de medidas adoptado por la Unión Europea en el marco de la Estrategia para el Mercado Único Digital y que viene a complementar el ámbito de aplicación de la Directiva 2006/123 relativa a los servicios en el mercado interior ${ }^{22}$, contribuyendo a clarificar aquellas situaciones en las que no puede justificarse un trato diferente por razón de la nacionalidad, del

${ }^{20}$ Vid, el documento de la Comisión Europea "Preguntas y respuestas relativas al Reglamento sobre bloqueo geográfico en el contexto del comercio electrónico", 2018, disponible en https://ec.europa.eu/digital-single-market/en/news/geo-blocking-regulation-questions-and-answers.

${ }^{21}$ Vid., documento SWD (2016) 173 final, de 25.05.2016, Commission staff working document, Impact assessment, Accompanying the document proposal for a Regulation of the European Parliament and of the Council on adressing geo-blocking and other forms of discriminiation based on place of residence or establishment or nationality within the Single Market, apartado 2.3 , p. 15 .

${ }^{22}$ Directiva 2006/123/CE del Parlamento Europeo y del Consejo de 12 de diciembre de 2006 relativa a los servicios en el mercado interior (DOUE L 376, de 27.12.2006) (en adelante, la Directiva relativa a los servicios en el mercado interior). 
lugar de residencia o del lugar de establecimiento, tal y como señala la mencionada Directiva ${ }^{23}$. De cualquier modo, hay que tener en cuenta que en caso de conflicto de las disposiciones del Reglamento con las de la mencionada Directiva prevalecerá el primero.

10. El Reglamento se encuentra directamente relacionado con los contratos de suministro de contenidos digitales y de compraventa de bienes y su objetivo principal es contribuir a mejorar el funcionamiento del mercado interior. Para ello, pretende poner fin al bloqueo geográfico injustificado y otras formas de discriminación basadas, directa o indirectamente, en la nacionalidad ${ }^{24}$, el lugar de residencia o el lugar de establecimiento de los clientes ${ }^{25}$, siempre que no se encuentren justificadas objetivamente ${ }^{26}$. Todo ello, sin perjuicio del respeto a la libertad contractual de las empresas para desarrollar sus actividades comerciales, incluida la libertad para organizar su política comercial, que forman parte de los derecho fundamentales reconocidos tanto por el Derecho de la Unión Europea ${ }^{27}$ cuanto por los distintos derechos nacionales ${ }^{28}$ tal y como ha sido reconocido en la jurisprudencia del TJUE ${ }^{29}$. Consecuentemente, la libertad contractual debe permitir al comerciante ofrecer sus servicios en aquellos Estados que considere oportunos y restringir la contratación con determinados consumidores, salvo que la misma pueda quedar limitada por razones justificadas -ya sea por discriminación por motivos de raza, sexo...-, o porque de no hacerlo se pondrían en peligro necesidades básicas de la población ${ }^{30}$.

11. Su ámbito de aplicación, que alcanza a todos los Estados parte en el EEE, se circunscribe a situaciones transfronterizas donde intervienen elementos conectados con distintos ordenamientos jurídicos -nacionalidad o lugar de residencia del consumnidor, lugar de establecimiento del comerciante, lugar de ejecución del contrato, medios de pago utilizados...- no siendo de aplicación a situaciones puramente internas de un Estado miembro ${ }^{31}$. De esta suerte, todo profesional-comerciante o prestador de servicios que desarrolle su actividad en el mercado de la Unión Europea ${ }^{32}$ viene obligado a cumplir

${ }^{23}$ El artículo 20.2 de la Directiva relativa a los servicios en el mercado interior dispone: “1. Los Estados miembros harán lo necesario para que el destinatario no se vea sujeto a requisitos discriminatorios basados en su nacionalidad o en su lugar de residencia. 2. Los Estados miembros harán lo necesario para que las condiciones generales de acceso a un servicio que el prestador ponga a disposición del público no contengan condiciones discriminatorias basadas en la nacionalidad o el lugar de residencia del destinatario, sin que ello menoscabe la posibilidad de establecer diferencias en las condiciones de acceso directamente justificadas por criterios objetivos".

${ }^{24}$ La prohibición de discriminación por motivos de nacionalidad es un principio general del Derecho de la Unión. Vid., al respecto, los artículos 18 del TFUE y 21.2 de la Carta de los Derechos Fundamentales de la Unión Europea.

${ }^{25}$ Artículo 1.1 y Considerando 4 del Reglamento sobre bloqueo geográfico.

${ }^{26}$ El documento de la Comisión "Preguntas y respuestas ...", doc. cit., apartado 2.1.1, p. 10, señala: "Las justificaciones objetivas se pueden relacionar ... con la ausencia de los derechos de propiedad intelectual exigidos en un territorio concreto, los costes adicionales ocasionados por la distancia o las características técnicas de la prestación, o las diferencias en las condiciones del mercado, como una demanda más o menos elevada influenciada por la temporalidad, los diferentes periodos vacacionales de los Estados miembros o las distintas politicas de precios por parte de los competidores". Vid., en el mismo sentido, el Considerando 95 de la Directiva relativa a los servicios en el mercado interior, donde se relacionan una serie de actuaciones que podrían justificar la diferencia de trato.

${ }^{27}$ El artículo 16 de la Carta de los Derecho fundamentales de la Unión Europea reconoce la libertad de empresa y dispone: "Se reconoce la libertad de empresa de conformidad con el Derecho comunitario y con las legislaciones y prácticas nacionales". Vid., https://eur-lex.europa.eu/legal-content/ES/TXT/?uri=LEGISSUM\%3A133501

${ }^{28} \mathrm{Vid}$., al respecto el estudio del Parlamento Europeo, "Discrimination of the Consumers in the Digital Single Market", Directorate-General for Internal Policies, November 2013, p. 29, disponible en www.europarl.europa.eu/...consumers_/discrim consumers_en.pd.

${ }^{29}$ Vid., las Sentencias del TJUE, de 16 de enero de 1979, asunto C-151/78, Nykøbing, Rec. 1979, pag. 00001, par. 20; de 5 de octubre de 1999, asunto C-240/97 Spain c. Commission, Rec. 1999, pag. I-6571, par. 99; de 13 de diciembre de 1979, asunto C-44/79, Hauer, Rec. 1979, p. 03727, par. 31 a 33; de 11 de julio de 1989, asunto C-265/87, Schraeder, Rec. 1989, p. 02237, par. 15; y de 10 de julio de 1991, asuntos C-90/90 y C-91/90, Neu, Rec. 1991, pag. I-03617, par. 13.

${ }^{30}$ Vid., el estudio del Parlamento Europeo, "Discrimination of the Consumers...", doc. cit., p. 30. En el mismo sentido, se manifiesta el documento de la Comisión "Preguntas y respuestas...”, doc. cit., ap. 2.3.1, p. 21 al señalar que el Reglamento no impone a los comerciantes la obligación de vender pero sí la de no discriminar.

${ }^{31}$ Considerando 7 del Reglamento sobre bloqueo geográfico.

${ }^{32}$ Ibidem, artículo 2, apartado 18, que define al comerciante como “... toda persona física o jurídica, ya sea privada o pública, que actúe, incluso a través de otra persona que actúe en su nombre o a su cargo, con fines relacionados con su actividad comercial, negocio, oficio o profesión". 
con las disposiciones de este Reglamento, siendo indiferente que se encuentre domiciliado en un Estado miembro o en un tercer Estado ${ }^{33}$. Se garantiza, de esta forma, una competencia leal y en pie de igualdad para todos los operadores que actuen en el ámbito territorial del Reglamento.

A su vez, esta norma otorga protección a los clientes, ya se trate de consumidores -nacionales de un Estado miembro o nacionales de terceros Estados con residencia habitual en un Estado miembro-, o de empresas -que tengan su establecimiento en un Estado miembro- siempre que adquieran un producto o reciban un servicio en el territorio de la Unión Europea en el que residen o se encuentran temporalmente, para su uso final ${ }^{34}$.

Por otra parte, si bien el Reglamento no se aplica a las actividades excluidas del ámbito de aplicación de la Directiva relativa a los servicios en el mercado interior ${ }^{35}$-por ejemplo, los servicios en el ámbito del transporte, los servicios financieros, los servicios audiovisuales o los relacionados con el sector del juego-, su contenido resulta de gran relevancia ya que puede afectar, de una parte, a la protección de los derechos del consumidor y, de otra, de los comerciantes, especialmente las pequeñas y medianas empresas.

En fin, el Reglamento se aplica tanto a las ventas on line cuanto off line, por lo que abarca, igualmente, aquellas transacciones que se realicen a través de lo que se denominan canales integrados (multicanal).

\section{Obligaciones que impone el Reglamento a los comerciantes}

12. Para poner fin al bloqueo geográfico injustificado y otras formas de discriminación, el Reglamento impone las siguientes obligaciones a los comerciantes y prestadores de servicios que, a su vez, se traducen en derechos para los consumidores.

\section{A) Permitir el acceso a sus interfaces en línea}

13. Desde la entrada en vigor de esta norma, los comerciantes no pueden bloquear o limitar el acceso de los clientes a sus interfaces en línea ${ }^{36}$ en las distintas versiones linguisticas en que se encuentren redactadas. En la práctica, pues, los comerciantes han de diseñar y adaptar sus infterfaces en línea para que técnicamente puedan ser accesibles y permitan contratar fácilmente a los clientes domiciliados en otros Estados miembro. Queda prohibido, de este modo, el bloqueo geográfico injustificado y otras formas de discriminación basadas en la nacionalidad, el lugar de residencia o de establecimiento de los clientes $^{37}$, ya sea mediante el uso de medidas tecnológicas o de otro tipo.

14. Tampoco podrán los comerciantes redirigir a los clientes a una versión de su interfaz en línea diferente de aquella a la que accedieron inicialmente, salvo que medie su consentimiento expreso ${ }^{38}$. Este consentimiento, una vez otorgado, será válido para las sucesivas visitas del cliente a la misma interfaz en línea, pero podrá ser retirado en cualquier momento ${ }^{39}$. El Reglamento, sin embargo, guarda silencio sobre la forma en que el comerciante puede almacenar el consentimiento que el cliente otorgue a esa

${ }^{33}$ Artículo 18.1 del Reglamento Bruselas I bis. Vid., en este sentido, las Sentencias del TJUE de 19 de enero de 1993, asunto C-89/91, Hutton, Rec. 1993, p. I-00139; de 14 de noviembre de 2013, asunto C478/12, Maletic, ECLI:EU:C:2013:735; y de 28 de enero de 2015, asunto C-375/13, Kolassa, ECLI:EU:C:2015:37.

${ }^{34}$ Artículo 2, apartado 13, del Reglamento sobre bloqueo geográfico y artículo 2, apartado 12, donde se define al consumidor como "toda persona fisica que actúe con fines ajenos a su actividad comercial, negocio9, oficio o profesión".

${ }^{35} \mathrm{Ibidem}$, artículo 1.3, en el que excluye de su ámbito de aplicación las actividades mencionadas en el artículo 2.2 de la Directiva relativa a los servicios en el mercado interior.

${ }^{36}$ Ibidem, artículo 1, apartado 16, que define "interfaz en línea" como "cualquier tipo de programa informático, incluidos los sitios web o parte de ellos y las aplicaciones, incluidas las aplicaciones móviles, utilizado por un comerciante o en nombre de este, que sirva para dar a los clientes acceso a los productos o servicios del comerciante con vistas a iniciar una operación con respecto a dichos productos o servicios.

${ }^{37}$ Ibidem, artículo 3.1.

${ }^{38}$ Ibidem, artículo 3.2

${ }^{39}$ Ibidem, en su Considerando 20. Vid., igualmente, el documento de la Comisión "Preguntas y respuestas ....", doc. cit., apartado 2.2.3, p. 19 . 
redirección con el fin de recordarlo en futuros accesos a su interfaz en línea. En este contexto, habrá que considerar el uso de cookies para esa función ${ }^{40}$ teniendo en cuenta que el Reglamento dispone que en caso de redirección con el consentimiento expreso del cliente el posterior acceso a esa interfaz ha de ser fácilmente accesible para el cliente ${ }^{41}$.

15. Sensu contrario, los comerciantes pueden ofertar sus productos o servicios en diferentes territorios o, únicamente, a determinados grupos de clientes a través de ofertas específicas y condiciones generales de acceso diferentes a las que ofrece en otros Estados miembros. Para ello, podrán confeccionar diferentes interfaces en línea adaptadas a cada territorio o grupo de clientes. La conditio sine qua non para poder hacerlo será que el trato a los clientes no sea discriminatorio por motivos relacionados con la nacionalidad, el lugar de residencia o el de establecimiento del cliente.

Además, los comerciantes podrán aplicar condiciones de acceso diferentes por motivos no relacionados con la nacionalidad, el lugar de residencia o el de establecimiento del cliente; este podría ser el caso de la pertenencia de los clientes a una determinada asociación o por las contribuciones que han realizado al comerciante ${ }^{42}$.

16. Todo esto ha de entenderse sin perjuicio de la aplicación del bloqueo geográfico o la limitación de acceso o redirección, que será posible cuando estas acciones estén justificadas por la aplicación del Derecho de la Unión Europea o la legislación de un Estado miembro conforme al Derecho de la Unión al que las actividades del comerciante estén sujetas. En esos casos, el comerciante ha de explicar claramente las razones del bloqueo, de la limitación de acceso o de la redirección en el idioma de la interfaz en línea a la que el cliente ha tratado de acceder ${ }^{43}$, por ejemplo, indicando la disposición legal de que se trata o, simplemente, que el bloqueo responde a motivos de protección de los derechos de autor, de normas específicas de protección de la seguridad, ...

\section{B) No aplicar condiciones de acceso diferentes a sus productos y servicios}

17. En relación a las condiciones generales de acceso a los productos y servicios ${ }^{44}$, el Reglamento no permite que el comerciante aplique condiciones diferentes por motivos relacionados con la nacionalidad, el lugar de residencia o de establecimiento del cliente ${ }^{45}$.

18. Empero, esta prohibición no será óbice para que los comerciantes puedan ofrecer condiciones de acceso diferentes a sus productos, dependiendo del Estado miembro al que se dirijan o incluso dentro de un Estado miembro, y que se ofrezcan a los clientes de un determinado territorio o a grupos específicos de clientes siempre que sea de forma no discriminatoria ${ }^{46}$. De esta manera, el comerciente podría variar los precios de sus productos dependiendo del territorio al que se dirija.

Pensemos en un consumidor domiciliado en España que desea adquirir un producto y accede a la interfaz en línea francesa de una empresa localizada en Francia en lugar de hacerlo a su interfaz española. El motivo: porque el cliente español ha descubierto que la web francesa ofrece mejores condiciones económicas para el producto que busca. Como he señalado anteriormente, la prohibición de discriminación en relación al acceso a la interfaz del comerciante no implica que éste no pueda establecer condiciones de acceso diferentes, por ejemplo, en los precios de sus productos. Por este motivo, el consumidor español que decide adquirirlo a través de la web francesa lo hará en las mismas condiciones que un consumidor

\footnotetext{
${ }^{40}$ Ibidem, apartado 2.2 .7 , p. 20.

${ }^{41}$ Artículo 3.2 del Reglamento sobre bloqueo geográfico.

${ }^{42}$ Ibidem, en su Considerando 27.

43 Ibidem, artículo 3.3 y Considerandos 21 y 31.

${ }^{44}$ Ibidem, en su artículo 2.14, donde define las condiciones generales de acceso como "todas las condiciones y otros datos, como los precios netos de venta, que regulen el acceso de los clientes a los productos o servicios ofrecidos a la venta por un comerciante, que se establezcan, se apliquen y se pongan a disposición del público en general por parte del comerciante o en su nombre y que se apliquen a falta de un acuerdo negociado individualmente entre el comerciante y el cliente".

${ }^{45}$ Ibidem, artículo 4.1.

${ }^{46}$ Ibidem, artículo 4.2.
} 
francés domiciliado en Francia. Consecuentemente, la web francesa tiene que ser accesible desde el territorio español en virtud de la aplicación del Reglamento salvo que su bloqueo estuviese justificado por motivos legales. Y el consumidor español tampoco podrá ser redirigido a la versión española de la interfaz francesa que originariamente visitó salvo que mediase su consentimiento expreso.

19. Del mismo modo, la observancia de esta prohibición tampoco supone que el comerciante deba cumplir los requisitos legales nacionales no contractuales aplicables en el Estado miembro del domicilio del cliente en relación con los productos y servicios que ofrece, o de informar a la clientela sobre estos requisitos ${ }^{47}$, tal y como desarrollaré más adelante.

20. En fin, cuando el Derecho de la Unión Europea o la legislación de un Estado miembro de conformidad con el Derecho de la Unión impida a un comerciante vender o prestar servicios a determinados clientes o a clientes situados en un determinado territorio, resulta evidente que la aplicación de la prohibición de discriminación en relación al acceso a productos y servicios que el Reglamento establece queda fuera de lugar ${ }^{48}$.

Así pues, en relación a las condiciones de acceso a los productos y servicios, el Reglamento contempla y regula las siguientes situaciones:

\section{a) Adquisición de productos con entrega física en la zona determinada por el comerciante}

21. Cuando se trate de la adquisición de productos por vía electrónica que comprendan su entrega física, el Reglamento obliga al comerciante a no establecer condiciones diferentes por motivos relacionados con la nacionalidad o con el lugar de residencia o establecimiento del cliente. Esto significa que ha de permitir que los clientes adquieran el producto en las mismas condiciones que los residentes del Estado miembro en el que el comerciante ofrece los servicios de entrega.

No obstante, el Reglamento permite al comerciante designar el lugar en el que va a ofrecer el servicio de entrega o bien acordarlo con el cliente de conformidad con las condiciones generales de acceso $^{49}$. Dicho de otro modo, el comerciante no está obligado a entregar los productos en el Estado miembro del domicilio del cliente si en las condiciones generales de acceso el mencionado territorio no está comprendido entre los lugares de entrega. En estos casos, el consumidor que ha celebrado un contrato por vía electrónica, mediante el acceso a la interfaz del comerciante desde el Estado miembro en el que se encuentra domiciliado, tendrá que organizar la recogida del producto en un Estado miembro diferente al de su domicilio.

Así, por ejemplo, cuando la web de un comerciante francés no ofrezca la posibilidad de entregar sus productos en España pero sí en territorio francés y portugués, los consumidores españoles o domiciliados en España podrán contratar a través de la interfaz francesa o su versión española pero tendrán que desplazarse a los lugares designados por el comerciante -Francia o Portugal-para recoger el producto, ya que la obligación que el Reglamento impone a los comerciantes se limita a permitir el acceso a su interfaz y a poder adquirir sus productos pero no les obliga a entregar los mismos fuera de los territorios designados al efecto. En definiva, el comerciante francés podrá excluir el territorio español del ámbito geográfico de entrega de sus productos pero no que los consumidores españoles o domiciliados en España puedan acceder a su interfaz en línea, solicitar sus productos o servicios desde el territorio español y, posteriormente, recoger los mismos en el lugar donde ofrece sus servicios de entrega.

\section{b) Servicios que se prestan por vía electrónica y no requieren entrega física}

22. Igualmente, el Reglamento dispone que los comerciantes no pueden aplicar condicions generales de acceso discriminatorias a los servicios que se prestan por vía electrónica ${ }^{50}$. Estos servicios

\footnotetext{
47 Ibidem, artículo 4.3.

48 Ibidem, artículo 4.5.

49 Ibidem, artículo 4.1 a) y Considerandos 23 y 28 .

50 Ibidem, en su artículo 2, apartado 1, que define los servicios prestados por vía electrónica como “los servicios prestados
} 
pueden incluir: los servicios en la nube, los servicios de almacenamiento de datos, el alojamiento de sitios web y la provisión de cortafuegos, el uso de motores de búsqueda y directorios de internet, el suministro de sitios web, el mantenimiento a distancia de programas y equipos, y la administración de sistemas remotos ${ }^{51}$. De esta manera, los clientes han de poder acceder a estos servicios en las mismas condiciones que lo hacen los clientes locales del Estado en el que se encuentre establecido el prestador del servicio.

23. Ahora bien, cuando se trate de recibir servicios en línea "cuya característica principal sea proporcionar acceso a obras protegidas por derechos de autor o a otras prestaciones protegidas, $y$ permitir su utilización, incluida la venta de obras protegidas por derechos de autor o a otras prestaciones protegidas que no tengan soporte material" 52 , y no requieren entrega física, por ejemplo, libros electrónicos, videojuegos en línea, transmisión de música y software, no se aplicará la prohibición de discriminación prevista en el Reglamento, ya que el mismo hace compatible la prohibición de establecer condiciones discriminatorias de acceso a sus productos y servicios con el hecho de que el comerciante pueda ofrecer condiciones de acceso diferentes dependiendo del Estado miembro o del grupo de clientes de que se trate, siempre que no se haga de forma discriminatoria ${ }^{53}$.

Sin embargo, la prestación de servicios de contenido no audiovisual protegidos por derechos de autor queda sujeta al resto de disposiciones del Reglamento. Esto significa que los proveedores de servicios no pueden bloquear o limitar el acceso a sus interfaces en línea por razón de la nacionalidad, del lugar de residencia o del lugar de establecimiento de los clientes ${ }^{54}$.

\section{c) Servicios que no se prestan por vía electrónica y que el cliente recibe en un lugar físico}

24. Por su parte, cuando se contraten por vía electrónica servicios que no se prestan por vía electrónica sino de forma presencial en el Estado miembro en el que el comerciante desarrolla su actividad, por lo tanto, en un lugar físico diferente al lugar del domicilio o residencia habitual del cliente (verbigracia, la contratación con hoteles, restaurantes, empresas de alquiler de vehículos...), serán de aplicación los mismos requisitos señalados anteriormente, a saber: i) la no discriminación por razón de la nacionalidad, el lugar de residencia o el lugar de establecimiento del cliente; ii) la posibilidad de establecer condiciones generales que difieran entre Estados miembros o entre clientes de un determinado territorio y; iii) la no sujección del comerciante a los requisitos legales no contractuales del Estado miembro del domicilio o residencia habitual del cliente ${ }^{55}$.

De tal forma que cuando una consumidora española desee reservar un hotel en Roma podrá acceder desde España a la web del mencionado hotel a través de su interfaz italiana sin que pueda ser discriminada al efecto, sino que será tratada en condiciones equivalentes a una consumidora italiana domiciliada en Italia; y tampoco podrá ser redirigida a la web española del mencionado hotel si no consta su consentimiento expreso. Actuando así, la consumidora española evitaría la aplicación de las condiciones generales que ofrece la web española, que podrían ser diferentes y menos ventajosas que las ofrecidas por la web italiana al amparo de lo dispuesto en el Reglamento que permite a los comerciantes ofrecer condiciones de venta diferentes, por ejemplo, el precio del producto, a los clientes de un determinado territorio o a un grupo específico de clientes siempre que lo haga de forma no discriminatoria ${ }^{56}$.

\footnotetext{
a través de internet o de una red electrónica que, por su naturaleza, se presten de manera básicamente automatizada y con una intervención humana mínima, y sin que se puedan garantizar a falta de tecnología de la información".

${ }^{51}$ Ibidem, Considerando 24. Vid., igualmente, el Documento de la Comisión "Preguntas y respuestas,...", doc. cit., apartado. 2.1.16, pag. 16 .

${ }^{52}$ Ibidem, artículo 4.1 b) y Considerando 27.

53 Precisamente, el informe sobre la primera evaluación del Reglamento que presente la Comisión, a más tardar el 23 de marzo de 2020, examinará si debe ampliarse el ámbito de aplicación a estos servicios. Vid., el artículo 9 y el Considerando 37 del Reglamento sobre el bloqueo geográfico.

${ }^{54}$ Vid., el Documento de la Comisión, "Preguntas y respuestas, ...”, doc. cit., ap. 2.1.18, p. 17.

${ }_{55}$ Artículo 4.1 c) y Considerando 25 del Reglamento sobre bloqueo geográfico.

${ }^{56}$ Ibidem, artículo 4.2 y Considerando 27.
} 


\section{No aplicar condiciones discriminatorias por motivos relacionados con el pago}

25. Otra de las cuestiones que regula el Reglamento es la prohibibición de discrininacion relacionada con los medios de pago. En la práctica, esto supone que cuando concurran las siguientes condiciones:

i) que la operación de pago se efectue a través de una transacción electrónica, ya sea mediante transferencia, adeudo domiciliado o tarjeta;

ii) que se cumplan los requisitos de autenticación previstos en la Directiva 2015/2366 ${ }^{57}$; y

iii) que las operaciones de pago se efectúen en una moneda que sea aceptada por el comerciante,

los comerciantes no podrán rechazar determinadas transacciones comerciales o aplicar condiciones diferentes de pago por motivos relacionados con la nacionalidad, con el lugar de residencia o el lugar de establecimiento del cliente, con la ubicación de la cuenta de pago, con el lugar de establecimiento del proveedor de servicios de pago o con el lugar de emisión del instrumento de pago en la Unión Europea ${ }^{58}$.

26. Esto no significa que los comerciantes no puedan elegir libremente los medios de pago que deseen aceptar en las transacciones con sus clientes. Al contrario, gozan de plena libertad para determinar en sus interfaces en línea los medios de pago que admiten en sus transacciones comerciales siempre que lo hagan de modo no discriminatorio.

Ahora bien, una vez elegido el instrumento de pago basado en una tarjeta de una marca y una categoría de pago determinadas -tarjetas de débito, de crédito, personales o comerciales-, conforme a la libertad que le otorga el Derecho de la Unión Europea ${ }^{59}$ y rechazado el resto, los comerciantes no pueden aplicar condiciones discriminatorias, ya sea rechazando determinadas transacciones o aplicando condiciones de pago diferentes a esas transacciones.

Empero, un comerciante que utilice servicios de iniciación de pagos tal y como se definen en la Directiva (UE) 2015/2366 no estará obligado a aceptar el pago si ello implica celebrar un nuevo contrato o modificar uno existente con un proveedor de servicios de iniciación de pago ${ }^{60}$.

27. Dicho esto, hay que advertir que esta prohibición de no discriminación por motivos relacionados con el pago no obsta para que, en casos justificados por razones objetivas, el comerciante pueda:

i) aplazar la entrega de los productos o la prestación del servicio hasta que tenga constancia de que la operación de pago se ha iniciado correctamente cuando se trate de casos justificados por razones objetivas ${ }^{61} ; \mathrm{o}$

ii) reclamar el abono de gastos por la utilización de instrumentos de pago basados en tarjetas cuando estos sean superiores a los que soporta por el uso del mencionado medio de pago ${ }^{62}$.

\section{No permitir acuerdos sobre ventas pasivas que infrinjan la prohibición del bloqueo geográfico}

28. Con el fin de garantizar la no injerencia del Reglamento en las normas de libre competencia previstas en el TFUE ${ }^{63}$, esta norma declara nulos de pleno derecho aquellos acuerdos que impongan a los

${ }^{57} \mathrm{Vid}$., al respecto, los requisitos para la prueba de la autenticación y ejecución de las operaciones de pago que impone la Directiva (UE) 2015/2366 del Parlamento Europeo y del Consejo de 25 de noviembre de 2015 sobre servicios de pago en el mercado interior y por la que se modifican las Directivas 2002/65/CE, 2009/110/CE y 2013/36/UE y el Reglamento (UE) n ${ }^{\circ} 1093 / 2010$ y se deroga la Directiva 2007/64/CE (Texto pertinente a efectos del EEE) (DOUE L 337, de 23.12.2015), en su artículo 72.

${ }_{58}$ Artículo 5.1 del Reglamento sobre bloqueo geográfico.

59 Vid., el Reglamento (UE) 2015/751 del Parlamento Europeo y del Consejo, de 29 de abril de 2015, sobre las tasas de intercambio aplicadas a las operaciones de pago con tarjeta (DO L 123 de 19.5.2015), y la Directiva (UE) 2015/2366 del Parlamento Europeo y del Consejo, de 25 de noviembre de 2015, sobre servicios de pago en el mercado interior y por la que se modifican las Directivas 2002/65/CE, 2009/110/CE y 2013/36/UE y el Reglamento (UE) nº 1093/2010 y se deroga la Directiva 2007/64/CE (DO L 337 de 23.12.2015, p. 35).

${ }^{60}$ Considerando 32 del Reglamento sobre bloqueo geográfico.

${ }^{61}$ Ibidem, artículo 5.2.

${ }^{62}$ Ibidem, artículo 5.3 .

${ }^{63}$ Vid., al respecto, los artículos 101 y 102 del TFUE. 
comerciantes, con respecto a las ventas pasivas, la obligación de actuar incumpliendo las prohibiciones que establece el propio Reglamento ${ }^{64}$.

A modo de ejemplo, como disposiciones de esos acuerdos que deberían declararse nulas, el Reglamento señala las “... restricciones contractuales que impiden a un comerciante atender a solicitudes espontáneas de clientes individuales en relación con la venta de productos, sin entrega, fuera del territorio asignado contractualmente por motivos relacionados con la nacionalidad, el lugar de residencia o el lugar de establecimiento del cliente" ${ }^{\text {65. }}$.

Así las cosas, los comerciantes no podrán tratar de forma discriminatoria a los clientes de otros Estados miembros, ya sea negándose a darles acceso a sus productos o servicios o incumpliendo cualesquiera de las obligaciones que impone el Reglamento, por el hecho de haberlo incluido así en los contratos con sus proveedores. Consecuentemente, en las ventas pasivas los comerciantes han de tener libertad para atender las solicitudes de los clientes pero sin discriminarlos por razón de su nacionalidad o lugar de residencia.

29. Sensu contrario, habrá que entender que el Reglamento no afecta a los acuerdos que puedan restringir las ventas activas, es decir, aquellas en las que el comerciante se aproxima o dirige activamente a los clientes individuales, en el sentido de lo dispuesto en el Reglamento 330/2010 de exención por categorías para acuerdos verticales, cuando existan acuerdos de distribución exclusiva que se ajusten a las normas de competencia, acuerdos que en ningún caso podrán incluir la prohibición de acceso de los clientes a la interfaz en línea del comerciante ${ }^{66}$.

\section{Interacción del Reglamento con las normas de Derecho internacional privado}

30. Como he señalado anteriormente, el Reglamento reconoce implícitamente que el marco jurídico existente en materia de derecho internacional privado debe ser suficiente y sus disposiciones han de entenderse sin perjuicio del Derecho de la Unión relativo a la cooperación judicial en materia civil $\mathrm{y}$, en particular, de las disposiciones sobre la ley aplicable a las obligaciones contractuales y sobre la competencia judicial internacional ${ }^{67}$.

31. A pesar de ello, al definir su objeto y ámbito de aplicación, se refiere al concepto de "actividad dirigida" al Estado del domicilio o residencia habitual del consumidor, requisito cuyo cumplimiento imponen tanto el Reglamento Bruselas I bis ${ }^{68}$ cuanto el Reglamento Roma I ${ }^{69}$ para que el consumidor pueda demandar a la otra parte contratante ante los tribunales de su domicilio y resulte de aplicación la ley de su Estado.

Y lo hace en los siguientes términos:

“... Del cumplimiento del presente Reglamento no se derivará que un comerciante dirige sus actividades al Estado miembro de residencia habitual o domicilio del consumidor en el sentido del artículo 6, apartado 1, letra b), del Reglamento (CE) $n^{\circ}$ 593/2008 y del artículo 17, apartado 1, letra c), del Reglamento (UE) $n^{\circ}$ 1215/2012. En particular, cuando un comerciante, que actúa de conformidad con los artículos 3, 4 y 5 del presente Reglamento, no bloquea ni limita el acceso de los consumidores a su interfaz en línea, no redirige a los consumidores a una versión de su interfaz en línea basada en la nacio-

${ }^{64}$ Artículo 6 del Reglamento sobre bloqueo geográfico, que se refiere al incumplimiento de las prohibiciones establecidas en los artículos 3, 4 y 5. Con respecto a las ventas pasivas, Vid., el Reglamento (UE) n 330/2010 de la Comisión de 20 de abril de 2010 relativo a la aplicación del artículo 101, apartado 3, del Tratado de Funcionamiento de la Unión Europea a determinadas categorías de acuerdos verticales y prácticas concertadas concertadas (Texto pertinente a efectos del EEE) (DOUE L 102, de 23.4.2010), en particular, el artículo 4.

${ }^{65}$ Considerando 34 del Reglamento sobre bloqueo geográfico.

${ }^{66}$ Vid., el documento de la Comisión "Preguntas y respuestas...", doc. cit., apartado 2.5, p. 33.

${ }^{67}$ Considerando 13 del Reglamento sobre bloqueo geográfico.

${ }^{68}$ Artículo 17, apartado 1, letra c), del Reglamento Bruselas I bis.

${ }^{69}$ Artículo 6, apartado 1, letra b), del Reglamento Roma I. 
nalidad o lugar de residencia delos mismos diferente de la interfaz en línea a la que hubiesen tratado de acceder inicialmente, no aplica condiciones generales de acceso diferentes al vender productos o prestar servicios en los supuestos previstos en el presente Reglamento, o acepta instrumentos de pago emitidos en otro Estado miembro de manera no discriminatoria, no se considerará, únicamente por esos motivos, que dicho comerciante dirige sus actividades al Estado miembro en que el consumidor tiene su domicilio o residencia habitual.." ${ }^{70}$.

32. De esta manera, la controversia está servida, pues no estamos en presencia de una cuestión baladí considerando que la prohibición de las prácticas de bloqueo geográfico que el Reglamento establece afecta a todos los comerciantes que presten sus servicios en el territorio de la Unión Europea y que los contratos celebrados con consumidores representan una parte muy importante de esta actividad.

Y el Reglamento sobre bloqueo geográfico y, en particular, algunas de sus disposiciones, podrían repercutir de manera directa en el funcionamiento de importantes normas de nuestro sistema de Derecho internacional privado e interferir en lo que es o no relevante a efectos de la interpretación de los artículos 17.1 c) del Reglamento Bruselas I bis, y 6.1 b) del Reglamento Romal ${ }^{71}$.

33. Por consiguiente, a la luz del mencionado texto y de lo dispuesto tanto en los Reglamentos Bruselas I bis y Roma I cuanto en la jurisprudencia del TJUE en esta materia, pueden plantearse las siguientes cuestiones:

a) ¿Nos encontramos en presencia de una norma que complementa e interpreta los artículos 17.1 c) del Reglamento Bruselas I bis y 6.1 b) del Reglamento Roma I, teniendo en cuenta que en sus respectivos textos no definen ni delimitan el alcance del concepto "actividades dirigidas" al Estado del domicilio o residencia habitual del consumidor?

b) ¿Significa esto que, a tenor de lo dispuesto en los artículos 67 del Reglamento Bruselas I bis y 23 del Reglamento Roma $\mathrm{I}^{72}$, respecto a la relación de estos reglamentos con otras disposiciones de derecho comunitario, la definición de "actividades dirigidas" al Estado miembro del consumidor quedaría definida sensu contrario en el Reglamento sobre bloqueo geográfico injustificado, al menos por lo que a los servicios prestados por vía electrónica cubiertos por su ámbito de aplicación se refiere?

c) ¿Podría interpretarse la declaración contenida en el Reglamento sobre bloqueo geográfico como una interferencia en la doctrina del TJUE que ya ha tenido ocasión de interpretar el alcance y contenido del concepto de "actividades dirigidas" en algunas de sus decisiones con motivo de la interpretación del artículo 17.1 c) del Reglamento Bruselas I bis? ${ }^{73}$

d) En todo caso, ¿resultan compatibles con el Reglamento sobre bloqueo geográfico los indicios identificados por el TJUE en su jurisprudencia para determinar cuándo un comerciante, a través de su interfaz, está dirigiendo sus actividades al Estado miembro del domicilio o residencia habitual del consumidor? o, por el contrario, ¿la aplicación del Reglamento exige una relectura de estos indicios por parte del TJUE?

e) En fin, ¿cómo ha de interpretarse el contenido del artículo 1.6 del Reglamento sobre bloqueo geográfico cuando señala que del cumplimiento de sus disposiciones no puede inferirse que un comerciante dirige sus actividades al Estado miembro de residencia habitual o domicilio del consumidor en el sentido del artículo 6.1 b) del Reglamento Roma I y del artículo 17.1 c) del Reglamento Bruselas I bis?

\footnotetext{
${ }^{70}$ Artículo 1.6 y Considerando 13 del Reglamento sobre bloqueo geográfico.

${ }^{71}$ Vid., P. A. De Miguel Asensio, "El nuevo Reglamento de la Unión Europea sobre bloqueo geográfico y otras formas de discriminación (1)”, La Ley Unión Europea, n 59, de 31.05.2018, pp. 2 y 7.

72 Vid. los artículos 67 del Reglamento Bruselas I bis y 23 del Reglamento Roma I, que regulan las relaciones de estos instrumentos con otras disposiciones de Derecho comunitario en materia de competencia judicial y ley aplicable.

${ }^{73}$ Vid., al respecto, las Sentencias del TJUE de 7 de diciembre de 2010, Pammer y Hotel Alpenhof, asuntos acumulados C-585/08 y C-144/09, Rec. 2010, p. I-12527; de 6 de septiembre de 2012, Mühlleitner, asunto C-190/11, ECLI:EU:C:2012:542; de 17 de octubre de 2013, Emrek, asunto C-218/12, ECLI:EU:C:2013:666; y de 23 de diciembre de 2015, Kampik, asunto C-297/14, ECLI:EU:C:2015:844.
} 
34. En principio, hay que señalar que no estamos en presencia de un Reglamento que incorpore normas de conflicto de leyes en relación a los contratos de suministro de contenidos digitales y de compraventa de bienes, pues no es esta su finalidad sino la de "... contribuir al buen funcionamiento del mercado interior impidiendo el bloqueo geográfico injustificado y otras formas de discriminación basadas, directa o indirectamente, en la nacionalidad, el lugar de residencia o el lugar de establecimiento de los clientes..." 74 .

Precisamente, el propio Reglamento reconoce su aplicación sin perjuicio de las normas ya existentes en materia de derecho internacional privado y remite expresamente a lo dispuesto en los Reglamentos Bruselas I bis y Roma I, de manera que no ha de cuestionarse su aplicación frente a las mencionadas disposiciones de derecho internacional privado ni tampoco que esté procediendo a una interpretación de las mismas.

Por otra parte, resultaría cuanto menos rebatible que las disposiciones del Reglamento sobre bloqueo geográfico injustificado adoptadas en el marco de la política del mercado interior, tal y como reconoce su artículo 1, pudiesen modificar o limitar las normas de conflicto previstas en los Reglamentos Bruselas I bis y Roma I adoptadas en el marco de la cooperación judicial en materia civil ${ }^{75}$.

En cualquier caso, resulta evidente que su interpretación podría plantear problemas en el futuro, especialmente a los comerciantes que actualmente vienen desarrollando su actividad únicamente en una parte del territorio de la Unión Europea y, por este motivo, resulta necesario un análisis sobre el concepto de "actividades dirigidas" a la luz de la doctrina elaborada por el TJUE en su jurisprudencia y su interacción con las disposiciones del Reglamento sobre bloqueo geogáfico.

\section{El concepto de "actividades dirigidas al Estado miembro del domicilio o residencia habitual del consumidor"}

\section{Plantemiento}

35. Cuando un comerciante que presta sus servicios por vía electrónica ${ }^{76}$ orienta su actividad comercial a los consumidores domiciliados o con residencia habitual en un Estado miembro, se considera que desea trabajar o introducirse en ese territorio y que está dirigiendo sus actividades a ese mercado. Pero, para identificar estas situaciones, ¿será necesario que el comerciante dirija su oferta a los potenciales clientes mediante el envío de comunicaciones electrónicas u otras acciones o bastará el mero acceso del consumidor al sitio web donde oferta su actividad comercial o profesional?

Si bien el envío de comunicaciones a través del correo electrónico puede cumplir las condiciones necesarias para considerar que el prestador de servicios se ha dirigido al Estado miembro del domicilio o residencia habitual del consumidor, el mero acceso del consumidor a su web sería cuestionable puesto que esta no se dirige a una jurisdicción particular sino que es susceptible de ser consultada desde cualquier Estado en el que se pueda acceder a internet y este hecho no supone necesariamente que su titular esté dirigiendo sus actividades hacia todos esos Estados.

36. En este sentido, resulta interesante recordar que en un principio el concepto de "actividad dirigida" fue interpretado de una forma laxa en el texto de la Propuesta inicial del Reglamento 44/2001, donde la Comisión señalaba que la comercialización de bienes o servicios por un medio electrónico

\footnotetext{
${ }^{74}$ Artículo 1.1 del Reglamento sobre bloqueo geográfico. En el mismo sentido, Vid., el documento de la Comisión "Preguntas y respuestas...", doc. cit., apartado 3.2, p. 35.

${ }^{75}$ P. A. De Miguel Asensio, “El nuevo Reglamento de la Unión Europea sobre bloqueo...”, loc. cit., p. 6; y J. I. PAREDES PÉrez, "Medidas contra el bloqueo geográfico injustificado: el Reglamento (UE) 2018/302 y su incidencia sobre las normas europeas de Derecho internacional privado", Revista Electrónica de Estudios Internacionales, no 35, Junio, 2018, p. 14.

${ }^{76}$ El artículo 2.1 del Reglamento sobre bloqueo geográfico define los servicios prestados por vía electrónica como “... aquellos "servicios prestados a través de internet o de una red electrónica que, por su naturaleza, se presten de manera básicamente automatizada y con una intervención humana mínima, y sin que se puedan garantizar a falta de tecnología de la información".
} 
accesible en un Estado miembro constituía una "actividad dirigida a dicho Estado"77. A pesar de ello, esta redacción no prosperó y fue modificada por el Parlamento Europeo que consideró excesivas estas condiciones porque las mismas podrían condenar a los prestadores de servicios a verse demandados ante los tribunales de cualquier jurisdicción donde su web fuese accesible.

Por lo tanto, hasta que el TJUE tuvo ocasión de pronunciarse al respecto, el criterio que servía como guía en esta materia era la Declaración conjunta del Consejo y la Comisión relativa al artículo 15 del Reglamento 44/2001 en la que ambas instituciones afirmaban que "el mero hecho de que un sitio Internet sea accesible no basta para que el artículo 15 resulte aplicable, aunque se dé el hecho de que dicho sitio invite a la celebración de contratos a distancia y que se haya celebrado efectivamente uno de estos contratos a distancia, por el medio que fuere. A este respecto, la lengua o la divisa utilizada por un sitio Internet no constituye un elemento pertinente"78. En esta declaración se aprecia, de modo implícito, una referencia a la distinción entre webs interactivas y pasivas.

37. A mayor abundamiento, el Reglamento Roma I, al referirse a la coherencia que han de observar ambos textos legislativos -los Reglamentos Bruselas I bis y Roma I- señala que la lengua o la divisa que utilice una web no constituye un elemento pertinente al objeto de considerar que se cumple la condición de "actividad dirigida" y activar la norma que protege al consumidor ${ }^{79}$.

38. Precisamente, esta es la línea que sigue el Reglamento sobre bloqueo geográfico que garantiza la accesibilidad de los clientes a las interfaces en línea de los comerciantes desde cualquier lugar de la Unión Europea y, al mismo tiempo, advierte que el cumplimiento de sus disposiciones no implica que un comerciante está dirigiendo sus actividades al Estado miembro de residencia habitual o domicilio del consumidor.

Por esta razón, parece excesivo considerar que el prestador de servicios pueda verse sometido a la jurisdicción y a la ley del Estado miembro del domicilio o residencia habitual del consumidor con el que contrató por vía electrónica por el mero hecho de que éste hubiese accedido a su interfaz desde ese Estado, siempre que no quede probado por otros medios que el comerciante había dirigido sus actividades a ese mercado.

39. De no aplicar ese criterio, esta situación podría generar un efecto negativo en la contratación electrónica y una restricción importante en la comercialización transfronteriza, ya que los comerciantes que deseen evitar el sometimiento a la jurisdicción y a la ley del Estado del domicilio del consumidor en caso de conflicto -bien sea por la incertidumbre legal o por el coste económico que estas demandas llevan implícitas-, podrían renunciar al desarrollo de su actividad on line.

No obstante, antes de tomar esa decisión tendrán que valorar si la renuncia a desarrollar su actividad por vía electrónica con consumidores domiciliados en otros Estados miembros resulta rentable para sus empresas y tomar en consideración que para evitar posibles demandas ante tribunales extranjeros pueden recurrir a otros medios alternativos de resolución de controversias o a la posibilidad de pactar previamente con sus clientes la jurisdicción y la ley aplicable en caso de conflicto. Sin olvidar la existencia de otros instrumentos normativos que habilitan medidas para facilitar la solución de litigios transfronterizos en el territorio de la Unión Europea, por ejemplo, en los casos de títulos ejecutivos europeos, el proceso monitorio europeo, y el proceso europeo de escasa cuantía ${ }^{80}$.

\footnotetext{
${ }^{77}$ Considerando 13 de la Propuesta de Reglamento (CE) del Consejo relativo a la competencia judicial, al reconocimiento y a la ejecución de resoluciones judiciales en materia civil y mercantil, Documento COM (1999) 348 final, de 7.09.1999 (DOCE C 376 E, de 28.12.1999).

78 Vid., la Declaración conjunta del Consejo y de la Comisión relativa a los artículos 15 y 73 del Reglamento 44/2001, Documento 13742/00, disponible en http://ec.europa.eu/civiljustice/homepage/homepage_ec_es_declaration.pdf

${ }^{79}$ Considerando 24 del Reglamento Roma I.

${ }^{80}$ Vid., en este sentido, el Reglamento (CE) n 805/2004 del Parlamento Europeo y del Consejo, de 21 de abril de 2004, por el que se establece un título ejecutivo europeo para créditos no impugnados (DO L 143 de 30.4.2004); el Reglamento (CE) $\mathrm{n}^{\mathrm{o}}$ 1896/2006 del Parlamento Europeo y del Consejo, de 12 de diciembre de 2006, por el que se establece un proceso monitorio europeo (DO L 399 de 30.12.2006); y el Reglamento (CE) n 861/2007 del Parlamento Europeo y del Consejo, de 11 de julio de 2007, por el que se establece un proceso europeo de escasa cuantía (DO n L 199 de 31.07.2007).
} 
40. Pues bien, con el fin de evitar ese problema, los comerciantes venían regulando el desarrollo de su actividad on line mediante el uso de herramientas relativamente sencillas como son el bloqueo geográfico o la inclusión de disclaimers o cláusulas de exención de responsabilidad en su web -de forma bien visible y accesible a los consumidores que visiten la misma- en la que advertían acerca de la limitación de su actividad respecto a determinados Estados o mercados y a los consumidores allí domiciliados ${ }^{81}$.

Hay que reconocer que estas prácticas limitaban las posibilidades de elección de los consumidores y no favorecerían la libre prestación de servicios, al contrario, fomentaban un fraccionamiento del mercado único y la discriminación de los consumidores en función de su domicilio en contra de lo que dispone la Directiva relativa a los servicios en el mercado interior ${ }^{82}$ y el propio Reglamento sobre bloqueo geográfico.

En el momento actual, y desde la entrada en vigor del Reglamento los comerciantes ya no pueden utilizar el bloqueo geográfico como una herramienta para acotar su mercado de actuación y evitar posibles demandas ante los tribunales y bajo la ley del Estado miembro del domicilio o residencia habitual del consumidor, por lo que habrán de buscar soluciones alternativas.

41. En mi opinión, la solución a este conflicto pasa por definir los mercados a los que los comerciantes dirigen su actividad de manera voluntaria y hacerlo compatible con la prohibición del bloqueo geográfico injustificado que impone el Reglamento, por ejemplo, delimitando el grado de interactividad de su website, así como la existencia o la ausencia de signos que puedan demostrar que ha dirigido sus actividades al Estado miembro del domicilio del consumidor.

Esto implica el análisis de aspectos concretos y específicos tales como las ofertas y publicidad que realice, el perfil de los consumidores a los que dirige sus productos o servicios, el idioma utilizado en la redacción de la web y la documentación que incorpora en la misma, la moneda utilizada para efectuar sus transacciones o las contrataciones reales efectuadas en ese Estado o Estados en los últimos tiempos ${ }^{83}$. Y, en cualquier caso, como sostiene parte de la doctrina, la carga de la prueba para demostrar que el comerciante ha dirigido su actividad hacía un determinado mercado recaerá sobre el consumidor que pretenda beneficiarse de la protección conferida por los Reglamentos Bruselas I bis y Roma I ${ }^{84}$.

Dicho esto, en determinados supuestos la limitación para contratar con consumidores con el fin de evitar posibles demandas ante los tribunales de los Estados donde se encuentran domiciliados podrá estar justificada cuando responda a causas objetivas y no discriminatorias tal y como prevé la mencionada Directiva ${ }^{85}$ y el Reglamento sobre bloqueo geográfico.

42. A partir de ahí, el hecho concluyente será la voluntad del prestador del servicio de acceder y dirigir su actividad a otros mercados (el denominado Internacional Stream-Of-Commerce) adoptando las medidas necesarias para conseguir un fin eminentemente económico. Teniendo en cuenta que no todos los elementos que coadyuvan al cumplimiento de ese fin tienen un efecto económico -por ejemplo, el nombre de dominio, la dirección de correo electrónico o el idioma utilizado en la web- se puede concluir que todo gira alrededor de la voluntad del comerciante o prestador de servicios ${ }^{86}$.

${ }^{81}$ Un buen ejemplo de este tipo de cláusulas o disclaimers, donde se especifican claramente los mercados o destinatarios de los productos, puede encontrarse en las páginas web de los prestadores de servicios financieros y, en concreto, de las entidades comercializadoras o las sociedades de gestión de fondos de inversión. Vid., al respecto, R. LAFuente SÁnchez, Contratos internacionales electrónicos de fondos de inversión, Marcial Pons, Madrid, 2008, pp. 345-349.

${ }^{82}$ Artículo 20 de la Directiva relativa a los servicios en el mercado interior.

${ }^{83}$ Vid., R. Lafuente Sánchez, Contratos internacionales electrónicos..., op. cit., p. 340.

${ }^{84}$ Vid., A. L. CALVo CARAVACA, "El Reglamento de Roma I sobre la ley aplicable a las obligaciones contractuales: cuestiones escogidas", Cuadernos de Derecho Transnacional (Octubre 2009), vol. 1, nº 2, p. 100, disponible en http://www.uc3m.es/cdt

${ }^{85} \mathrm{Vid}$., el Considerando 95 de la Directiva relativa a los servicios en el mercado interior, donde se incluye un listado de las posibles justificaciones para la diferencia de trato “... como los costes adicionales ocasionados por la distancia, las características técnicas de la prestación, diferencias en las condiciones del mercado, como una demanda más o menos elevada influenciada por temporalidad, distintos periodos de vacaciones en los Estados miembros o distintas políticas de precios por parte de los competidores, o los riesgos adicionales derivados de normativas distintas de las del Estado miembro de establecimiento. Tampoco cabe afirmar que la no prestación de un servicio a un consumidor por falta de los derechos de propiedad intelectual e industrial necesarios en un territorio particular suponga una discriminación ilegal”.

${ }^{86} \mathrm{Vid}$., F. F. WANG, Internet Jurisdiction and Choice of Law: Legal practices in the EU, US and China, Cambridge University Press, 2010, p. 62. 
Ahora bien, cabe plantear aquí si resulta suficiente que el prestador de servicios manifieste su voluntad de dirigir sus actividades a otro Estado miembro y, de ser así, cómo ha de exteriorizar la misma ¿bastará que sea de forma tácita o se requiere una manifestación expresa a través de la web?.

Asimismo, podría suceder que el comerciante no tuviese como objetivo dirigir sus actividades hacia los consumidores establecidos en otro Estado miembro y, sin embargo, el resultado final fuese la captación de los mismos. En estos casos, sería factible distinguir entre objetivo y resultado y concluir que, en ausencia de un objetivo claro y de indicios que así lo justifiquen, el prestador del servicio no habría dirigido sus actividades hacia el Estado del domicilio del consumidor ${ }^{87}$.

\section{Doctrina del TJUE en esta materia}

\section{A) Las "actividades dirigidas a un Estado miembro" como criterio de atribución de competencia judicial internacional}

43. El TJUE, a través de los asuntos Pammer y Alpenhof, Mühlleitner, Emrek y Kampik ha contribuido a clarificar el concepto de "actividades dirigidas" al Estado miembro del domicilio del consumidor. Si bien es cierto que todos ellos se circunscriben al ámbito de la competencia judicial internacional y a la interpretación del artículo $15.1 \mathrm{c}$ ) del Reglamento 44/2001 (actualmente artículo $17.1 \mathrm{c}$ ) del Reglamento Bruselas I bis que derogó al anterior) ${ }^{88}$, con el fin de definir los indicios relevantes para acreditar que un vendedor ha dirigido su actividad al Estado miembro del domicilio del consumidor, las conclusiones aportadas por el TJUE pueden ser extrapolables al ámbito de la ley aplicable a las obligaciones contractuales, y resultarán de gran ayuda a la hora de interpretar el artículo 6.1 c) del Reglamento Roma I y, en particular, la ley aplicable a los servicios prestados por vía electrónica en los que intervenga un consumidor.

44. Como podrá observarse, la jurisprudencia del TJUE protege de forma clara a la parte más débil en la relación contractual pues la interpretación de la expresión "dirigir las actividades" al Estado miembro del domicilio o residencia habitual del consumidor que ha llevado a cabo adquiere una dimensión muy amplia que puede o no coincidir con la voluntad real del comerciante o prestador del servicio. Esta afirmación tiene su fundamento en el amplio catálogo de indicios que (sin carácter exhaustivo, por lo que podrían ampliarse en un futuro) ha elaborado el TJUE para justificar que un comerciante (o su web) tiene la voluntad de dirigir su actividad hacia el Estado del domicilio del consumidor, si bien es cierto que habrá que evaluar y graduar en cada caso concreto la concurrencia de uno o varios de estos indicios.

Pese a ello, este enfoque ha sido cuestionado por algunos autores que consideran que el razonamiento del Tribunal debía haberse planteado desde la perspectiva contraria, es decir, partiendo de la idea del carácter global y universal que presenta la actividad contractual a través de internet, considerar que una vez concluida la contratación existe la presunción de que el prestador del servicio ha dirigido previamente sus actividades hacia el Estado miembro del domicilio del consumidor ${ }^{89}$, lo que favorecería aún más la protección del consumidor. A continuación, analizaré y sintetizaré estas decisiones.

87 Vid., D. J. B. Svantesson, "Pammer and Hotel Alpenhof - ECJ decisión creates further uncertainty about when e-businesses "direct activities" to a consumer's estate under the Brussels I Regulation”, Computer Law \& Security Review, 27 (2011), pp. 301-302.

${ }^{88}$ El artículo 15.1 c) del Reglamento (CE) $n^{\circ} 44 / 2001$ del Consejo, 22 de diciembre del 2000, relativo a la competencia judicial, el reconocimiento y la ejecución de resoluciones judiciales en materia civil y mercantil (DO n ${ }^{\circ}$ L 012 de 16.01.2001) dispone: "En materia de contratos celebrados por una persona, el consumidor, para un uso que pudiere considerarse ajeno a su actividad profesional, la competencia quedará determinada por la presente sección, sin perjuicio de lo dispuesto en el artículo 4 y en el punto 5 del artículo 5: c) en todos los demás casos, cuando la otra parte contratante ejerciere actividades comerciales o profesionales en el Estado miembro del domicilio del consumidor o, por cualquier medio, dirigiere tales actividades a dicho Estado miembro o a varios Estados miembros, incluido este último, y el contrato estuviere comprendido en el marco de dichas actividades".

${ }^{89}$ Vid., D. J. B. Svantesson, “Pammer and Hotel Alpenhof ...”, loc cit., pp. 302 y 304, quien considera que la conclusión del TJUE no es afortunada y que lejos de favorecer la protección del consumidor esta Sentencia perjudica tanto a los consumidores, al establecer un umbral de protección inferior al que sería deseable, cuanto a los prestadores de servicios, que a partir de ahora se verán sometidos a una mayor incertidumbre legal. 


\section{B) Indicios objetivos identificados por el TJUE para considerar que el comerciante ha dirigido sus actividades al Estado miembro del domicilio del consumidor.}

\section{a) Asunto Pammer y Alpenhof}

45. Hasta la Sentencia Pammer y Alpenhof, el TJUE no había tenido ocasión de analizar la expresión "dirigiese tales actividades a dicho Estado miembro o a varios Estados miembros" incluida en los Reglamentos Bruselas I bis y Roma I. De la misma se deduce que los indicios que pueden contribuir a demostrar que el prestador de servicios tiene voluntad de contratar con consumidores establecidos en otros Estados miembros pueden ser muy variados y, entre ellos, habrá que determinar cuáles son realmente indicativos de esta voluntad.

46. Tanto en el asunto Pammer, donde este ciudadano domiciliado en Austria había contratado a través de internet un viaje en carguero desde Trieste (Italia) hasta Asia Oriental con la empresa Reederei Kart Schlüter GMBH \& Co KG, con domicilio social en Alemania, a través de la web de la sociedad intermediaria Internationale Frachtschiffreisen Pfeiffer GMBH domiciliada en Alemania; cuanto en el asunto Alpenhof, donde el Sr. Heller, ciudadano residente en Alemania había realizado la reserva de varias habitaciones en el Hotel Alpenhof situado en Austria a través del correo electrónico que figuraba en la web del mencionado hotel, se plantearon sendas demandas relacionadas con los servicios contratados en las que se dilucidaba la competencia del forum actoris en la contratación electrónica B2C.

47. En su Sentencia, el TJUE descartaba que la mención en la web del vendedor de su dirección electrónica o postal o de su número de teléfono sin prefijo internacional pudiesen ser signos que evidencian su intención o voluntad de dirigir su actividad a otros Estados miembros, ya que se trata de elementos informativos que, en cualquier caso, resultan necesarios para permitir la comunicación entre el vendedor y los consumidores con independencia del lugar en el que estos últimos se encuentren domiciliados. No hay que olvidar que este tipo de información no es potestativa sino obligatoria para el prestador de servicios a través de internet en virtud de lo dispuesto en la Directiva sobre el comercio electrónico ${ }^{90}$.

48. Igualmente, señalaba el Tribunal que el hecho de que una página web sea accesible no basta per se para que resulte aplicable el artículo 15.1 c) del Reglamento 44/2001, ya que si el legislador hubiese querido que la mera existencia o accesibilidad a la página web del prestador de servicios fuese indicio suficiente para considerar que éste dirige sus actividades a cualquier Estado miembro desde el que el consumidor pueda acceder a la misma, podría haber adoptado una redacción diferente a la actualmente existente, pero no fue as $i^{91}$. Será necesario, por tanto, que concurran una serie de indicios objetivos para poder afirmar que ha dirigido sus actividades hacia el Estado del domicilio del consumidor.

49. En este sentido, cabía pensar que, al objeto de determinar si la página web del prestador de servicios dirigía su actividad comercial o profesional al Estado miembro del domicilio del consumidor, sería necesario analizar la función y configuración de la misma como una web interactiva o una web pasiva y, como elemento consustancial a esta distinción, la participación activa o pasiva del consumidor.

${ }^{90}$ Vid. el artículo 5. 1 c) de la Directiva 2000/31/CE del Parlamento Europeo y del Consejo, de 8 de junio de 2000, relativa a determinados aspectos jurídicos de los servicios de la sociedad de la información, en particular el comercio electrónico en el mercado interior (Directiva sobre el comercio electrónico) (DO L L 178, de 17/07/2000), que obliga al prestador del servicio a facilitar a los destinatarios del servicio, ex ante a la celebración del contrato, las señas que le permitan ponerse en contacto rápidamente con el prestador de servicios y establecer una comunicación directa y efectiva con él, incluyendo su dirección de correo electrónico. El TJUE ha tenido ocasión de interpretar el alcance de esta obligación en su Sentencia de 16 octubre 2008, Deutsche Internet Versicherung AG, 298/07, Rec. 2008, p. I-07841. Vid., al respecto, R. LAFUENTE SÁnChEZ; TJCE - Sentencia de 16.10.2008, Bundesverband / Deutsche internet versicherung AG, C-298/07; "Comercio electrónico - Prestador de servicios a través de internet - Correo electrónico" - Los prestadores de servicios en la sociedad de la información; Revista de Derecho Comunitario Europeo, ${ }^{\circ}$ 37, septiembre-diciembre 2010, pp. 917-931.

${ }^{91}$ Vid., los apartados 71, 73 y 74 de la Sentencia Pammer y Hotel Alpenhof y el apartado 64 de las Conclusiones de la Abogado general, Sra. Trstenjak, que se refieren al vigésimo cuarto considerando del Reglamento Roma I donde se menciona la Declaración conjunta del Consejo y la Comisión relativa al artículo 15 del Reglamento (CE) n 44/2001, doc. cit. 
Pero, el TJUE estimaba que no era determinante esta diferenciación, pues la inclusión en la web de los datos del prestador a los que antes me he referido y a los que viene obligado en virtud de la Directiva sobre el comercio electrónico - dirección electrónica o postal o número de teléfono- permiten al consumidor ponerse en contacto con él para la celebración del contrato. Y, de ese modo, se produce la convergencia en la operativa de las páginas web ya sean interactivas o pasivas por lo que el Tribunal rechazaba su distinción a los efectos que nos ocupa ${ }^{92}$.

50. Sin embargo, el TJUE consideraba que para dar respuesta a este interrogante había que definir y acotar los indicios que puedan aseverar que el prestador se ha esforzado activamente en captar clientes domiciliados en otros Estados miembros, en definitiva, que ese era el objetivo y el resultado de su actuación ${ }^{93}$.

Y afirmaba que los indicios objetivos han de ser "expresiones manifiestas de la voluntad de atraer a los consumidores" de otros Estados miembros diferentes a aquel en el que se encuentra establecida la otra parte contratante ${ }^{94}$, señalando con carácter meramente enunciativo los siguientes ${ }^{95}$ :

i) el carácter internacional de la actividad del prestador del servicio a desarrollar en el Estado de acogida;

ii) la descripción de itinerarios desde otros Estados miembros hasta el lugar de establecimiento del prestador del servicio;

iii) la posibilidad de utilizar en la contratación a través de la web una lengua diferente a la habitualmente empleada en el Estado miembro en el que se encuentra establecido el prestador del servicio, por ejemplo, la del país del Estado de acogida;

iv) la posibilidad de utilizar en la contratación a través de la web una moneda diferente a la habitualmente empleada en el Estado miembro en el que se encuentra establecido el prestador de servicios, por ejemplo, la del Estado del domicilio del consumidor;

v) la mención de números de teléfono con indicación del prefijo internacional;

vi) los gastos en un servicio de remisión a páginas web en internet que faciliten el acceso al sitio del prestador o sus intermediarios a consumidores de otros Estados miembros;

vii) la utilización de un nombre de dominio de primer nivel, por ejemplo, "es", "fr", "de", distinto al del Estado miembro de establecimiento del prestador del servicio, o neutros, por ejemplo, "com", "net", "org"; o

viii) la referencia a clientes (internacionales) domiciliados en otros Estados miembros.

Sensu contrario, entendía que los siguientes elementos no constituyen indicios que deban tomarse en consideración:

i) el mero acceso a la web del comerciante desde el domicilio del consumidor;

ii) el hecho de incorporar una dirección de correo electrónico y otros datos de contacto; o

iii) el uso de una lengua o de una divisa que habitualmente se emplean en el Estado miembro del comerciante.

\section{b) Asunto Mühlleitner}

51. En el asunto Mühlleitner se planteaba de nuevo la interpretación del artículo 15.1 c) del Reglamento 44/2001 pero, en esta ocasión, se dilucidaba la exigencia o no de que el contrato se hubiese celebrado a distancia para que el consumidor puediese activar la protección que le otorga el mencionado artículo y demandar al vendedor ante los tribunales de su domicilio.

${ }^{2}$ Vid., el apartado 79 de la Sentencia Pammer y Hotel Alpenhof y el apartado 63 de las Conclusiones de la Abogado general, Sra. Trstenjak.

${ }_{93}$ Vid. el apartado 75 de la Sentencia Pammer y Hotel Alpenhof y el apartado 63 de las Conclusiones de la Abogado General, Sra. Trstenjak.

${ }^{94}$ Ibidem, en su apartado 80 .

${ }^{95}$ Ibidem, apartados 80 a 84 . 
52. La Sra. Mühlleitner, domiciliada en Austria, buscaba en internet un vehículo automóvil. En una web alemana encontró un enlace a la página web de Ahmad Yusufi y Wadat Yusufi, titulares de un negocio de venta de automóviles al por menor a través de la sociedad Autohaus Yusufi GbR, domiciliada en Hamburgo (Alemania). La Sra. Mühlleitner contactó con la empresa a través del teléfono disponible en la web y, posteriormente, se desplazó hasta Hamburgo donde se firmó el contrato de compraventa en el domicilio del vendedor, adquiriendo el vehículo y procediendo al pago del mismo. Al descubrir varios defectos en el vehículo decidió reclamar a la empresa vendedora ante los tribunales de su domicilio en Austria.

53. En este asunto, el TJUE concluyó que la regla de competencia especial en materia de contratos celebrados por un consumidor será de aplicación con independencia de la forma que revista la conclusión del contrato, ya sea entre presentes o a distancia. Si bien esta afirmación resultaba hasta cierto punto previsible, pues tanto de los antecedentes y del tenor literal del mencionado precepto cuanto de la doctrina del TJUE no cabía inferir otra interpretación, no es menos cierto que la misma resultaba de gran relevancia para el desarrollo de la actividad económica por los vendedores profesionales que a partir de esta Sentencia tendrían que tener muy presentes las siguientes consideraciones:

i) En primer lugar, que lo determinante para que resulten competentes los tribunales del domicilio del consumidor, al socaire del foro especial en materia de contratos de consumo previsto en el Reglamento Bruselas I, será que los vendedores hayan dirigido su actividad por cualquier medio, y por supuesto a través de internet, al Estado del domicilio del consumidor de conformidad con la doctrina Pammer y Alpenhof;

ii) En segundo lugar, que cuando se cumpla ese requisito, será de aplicación el foro especial en materia de contratos de consumo con independencia de otras circunstancias, entre ellas, que el contrato se haya celebrado entre presentes o a distancia, o el lugar de celebración del mismo -ya sea en el Estado del domicilio del consumidor o en el del vendedor ${ }^{96}$.

54. En definitiva, esta Sentencia venía a complementar la doctrina del TJUE en susentencia Pammer y Alpenhof añadiendo otros elementos probatorios, como son la toma de contacto a distancia y la celebración de un contrato de consumo a distancia, que constituyen indicios de vinculación del contrato con la actividad comercial dirigida al Estado miembro del domicilio del consumidor ${ }^{97}$.

\section{c) Asunto Emrek}

55. Posteriormente, el asunto Emrek permitió al TJUE pronunciarse, de nuevo, sobre el artículo 15.1 c) del Reglamento 44/2001 y, en particular, juzgar si su aplicación exige la existencia de una relación causal entre la página web de un prestador de servicios que dirige su actividad comercial o profesional al Estado miembro del domicilio del consumidor y la posterior celebración del contrato.

56. El Sr. Emrek, domiciliado en Alemania, buscaba un vehículo de ocasión. Con este motivo, se desplazó hasta la ciudad francesa de Spicheren cercana a la frontera alemana donde el Sr. Sabranovic regentaba la empresa Vlado Automobiles Import-Export. Allí, adquirió un vehículo de ocasión y firmó el correspondiente contrato de compraventa. Esta empresa tenía una página web donde se mencionaba su dirección y se incluían los números de teléfono franceses y un número de teléfono móvil alemán, junto con los prefijos internacionales respectivos.

Con posterioridad, el Sr. Emrek demandó a la empresa vendedora en materia de garantía ante los tribunales de su domicilio en Alemania alegando que, aun cuando conoció la mencionada empresa por medio de conocidos y no de su web, del contenido de la misma se desprendía que su actividad comercial también estaba dirigida al mercado alemán.

${ }^{96}$ Vid., al respecto, mi trabajo R. LAfUEnTE SÁnChEZ, “Aplicación del régimen especial de protección de los consumidores previsto en el Reglamento Bruselas I a los contratos celebrados entre presentes: a propósito de la sentencia del TJUE de 6 de septiembre de 2012, asunto C-190/11, Mühlleitner, Diario La Ley, no 7966, 2012.

${ }^{97}$ Vid., apartado 44 de la Sentencia Mühlleitner. 
57. En primer lugar, el TJUE consideraba que el artículo $15.1 \mathrm{c}$ ) ha de interpretarse en el sentido de que "... no exije una relación causal entre el medio utilizado para dirigir la actividad comercial o profesional al Estado miembro del domicilio del consumidor, a saber, una página web, y la celebración del contrato con dicho consumidor", ya que incluir la relación causal como un requisito más para la aplicación del mencionado precepto no parece coherente con el objetivo que persigue esa disposición ${ }^{98}$.

Asimismo, estimaba que la prueba de una relación causal entre la web y la celebración del contrato podría plantear dificultades añadidas al consumidor y disuadirle de acudir a los tribunales de su domicilio con lo que se debilitaría la protección que se persigue con la aplicación de esta disposición ${ }^{99}$.

58. No obstante, el TJUE apreciaba que la existencia de esa relación causal puede constituir un indicio de vinculación del contrato a tal actividad, en definitiva, una señal de que el comerciante ha dirigido su actividad al Estado miembro del domicilio del consumidor, ${ }^{100}$ añadiendo, así, un elemento más al listado no exhaustivo de indicios probatorios elaborado en sus precedentes decisiones Pammer y Alpenhof, y Mühlleitner, para justificar que la actividad comercial se ha dirigido al Estado miembro del domicilio del consumidor.

\section{d) Asunto Kampik}

59. Finalmente, en el asunto Kampik el TJUE afrontaba como cuestión capital si el posible nexo entre dos contratos podía enmarcarse en el concepto de actividad dirigida al domicilio del consumidor en el sentido del artículo 15.1 c) del Reglamento 44/2001. La cuestión había surgido con ocasión de la existencia de dos contratos: el primero, concluido en el marco de la actividad de intermediación inmobiliaria que se había dirigido al Estado del domicilio del consumidor y, el segundo, un contrato de mandato considerado separadamente.

60. El Sr. Kampik, que desarrollaba su actividad profesional en España, intermedió entre el Sr. Hobohm y Kampik Immobilien KG (contrato de intermediación) para la adquisición de un apartamento situado en Denia (Alicante) que debía construir un promotor alemán. Estos apartamentos se comercializaban en Alemania a través de un folleto publicitario redactado en alemán.

Tras la firma del contrato de compraventa entre el vendedor (promotor alemán) y los compradores (matrimonio Hobohm), el Sr. Kampik ofreció a estos últimos encargarse de procurar la habitabilidad de la vivienda para lo cual el matrimonio Hobohm se desplazó a España y otorgó a favor del Sr. Kampik un poder notarial para la defensa de sus intereses en relación con el contrato de compraventa (contrato de mandato). Además, fueron entregando al Sr. Kampik determinadas cantidades con el fin de hacer frente al resto del pago del apartamento que habían adquirido.

Posteriormente, a consecuencia de la insolvencia del promotor y las desavenencias surgidas entre las parte en el contrato de mandato, el matrimonio Hobohm revocó el poder otorgado a favor del Sr. Kampik y lo demandaron ante los tribunales de su domicilio en Alemania con el fin de obtener la devolución de los importes que le habían entregado.

61. En esta ocasión, el TJUE declaró que, si bien el segundo contrato (el de mandato) no se inscribía en el ámbito de la actividad comercial dirigida al Estado miembro del domicilio del consumidor, había que tener en cuenta las siguientes consideraciones:

i) que el segundo contrato se había celebrado como prolongación directa de dicha actividad y era complementario del contrato de intermediación que sí respondía al criterio de actividad dirigida; $y$

ii) que a pesar de la falta de interdependencia jurídica entre ambos contratos, existía un nexo económico entre los mismos ${ }^{101}$.

\footnotetext{
${ }_{98}$ Sentencia Emrek, en su apartado 24.

${ }^{99}$ Ibidem, apartado 25.

${ }^{100}$ Ibidem, apartado 26.

${ }^{101}$ Sentencia Kampik, apartados 35 y 36.
} 
62. Por todo ello, el TJUE concluía que para examinar si existe un nexo causal entre el contrato de intermediación y el contrato de mandato, el órgano jurisdiccional remitente ha de tomar en consideración los siguientes elementos: i) si existe identidad fáctica o jurídica de las partes en ambos contratos; ii) si existe identidad del objetivo económico de los mismos; y iii) su posible complementariedad ${ }^{102}$.

De ser así, y teniendo en cuenta que el primer contrato (intermediación) se enmarcaba en el ámbito de la actividad del profesional dirigida al Estado del domicilio del consumidor, el posterior contrato (de mandato) que persigue el mismo objetivo que el primero quedaría sujeto al mismo régimen de competencia judicial internacional que el contrato inicial ${ }^{103}$. Por lo tanto, un indicio más de que el comerciante ha dirigido su actividad al Estado miembro del domicilio del consumidor que debe añadirse al listado que ha ido elaborando el TJUE en su doctrina.

\section{Análisis de los indicios identificados por el TJUE en su jurisprudencia a la luz del Reglamento sobre bloqueo geográfico injustificado}

\section{El acceso a la interfaz del comerciante desde el Estado del domicilio del consumidor no consti- tuye un indicio de que haya dirigido su actividad a ese país}

63. Como ya adelanté, a tenor de lo dispuesto en el Reglamento sobre bloqueo geográfico, la posibilidad de acceder a la web del comerciante desde cualquier Estado miembro no significa que dirige sus actividades hacia ese país. Y así, el hecho de que un comerciante no bloquee o limite el acceso de los consumidores a su interfaz en línea; o no aplique condiciones generales de acceso diferentes a sus bienes o servicios; o no aplique criterios discriminatorios en relación a los instrumentos de pago no será determinante para considerar que se ha cumplido el criterio del International Stream-Of-Commerce.

Esta afirmación coincide con lo manifestado por el TJUE en el asunto Pammer y Alpenhof ${ }^{104}$. En definitiva, la mera accesibilidad a la web no es suficiente para acreditar la voluntad del comerciante de dirigir sus actividades y realizar transacciones comerciales en un determinado mercado y con los consumidores allí domiciliados ${ }^{105}$, por lo que será preciso que concurra alguno de los indicios objetivos identificados por el TJUE en su jurisprudencia.

64. Como corolario de lo anterior, podría afirmarse que los comerciantes no están obligados a desarrollar su actividad en todo el territorio de la Unión Europea. Y, sin embargo, este hecho ha de ser compatible con la obligación de eliminar el bloqueo geográfico injustificado que impone el Reglamento, pues esta norma no empece la libertad comercial de la que disfrutan los comerciantes a la hora de organizar su actividad y que tendrá como límite la no discriminación por razón de la nacionalidad o el lugar de residencia o de establecimiento del cliente en aquellos mercados a los que haya decidido dirigirse.

65. No debe identificarse, por tanto, el acceso a la interfaz del comerciante desde el Estado miembro del domicilio del consumidor con la acción de "dirigir sus actividades" a ese mismo Estado. Ahora bien, ¿qué sentido tiene que los consumidores puedan acceder a la interfaz del comerciante desde su Estado de residencia al que no se ha dirigido su actividad?

En principio, con la prohibición del bloqueo geográfico se garantiza que el consumidor pueda conocer los productos o servicios que oferta el comerciante y que en el supuesto de estar interesado en los mismos pueda contratarlos a través de su web -cuando esta lo permita- o, en su defecto, a través de otros medios o de otra interfaz del comerciante. En estos casos, el consumidor ha de ser consciente de que en caso de conflicto no podrá beneficiarse del tratamiento más favorable que prevén las normas de Derecho internacional privado en los contratos concluidos con consumidores.

\footnotetext{
102 Ibidem, apartado 37.

${ }^{103}$ Ibidem, apartado 39.

${ }^{104}$ Vid., la Sentencia Pammer y Hotel Alpenhof, en sus apartados 71, 73, 74 y 94.

105 A. L. Calvo Caravaca y J. Carrascosa González, (Dirs.), Derecho internacional ..., op. cit., pp. 1124.
} 


\section{Coexistencia entre el acceso a su interfaz y la libertad del comerciante para excluir de la contra- tación a los clientes domiciliados en un Estado miembro}

66. El Reglamento dispone en sus considerandos que la prohibición de discriminación en cuanto al acceso a interfaces en línea no significa que el comerciante esté obligado a realizar transacciones con los clientes que accedan a su web ${ }^{106}$. Por otra parte, admite que el comerciante pueda diseñar sus ofertas de manera diferente y ofrecer condiciones generales de acceso que difieran en función del territorio o del grupo de clientes al que se dirigen -bien sean jóvenes, consumidores, profesionales....-siempre que sea de forma no discriminatoria ${ }^{107}$. Menos aún puede inferirse de alguna de sus disposiciones que el comerciante esté obligado a crear su interfaz en una determinada lengua o a facilitar diferentes versiones lingüísticas de la misma.

De las anteriores afirmaciones cabe inferir que el comerciante podrá excluir a los clientes domiciliados en uno o varios Estados miembros de la contratación de sus productos o servicios sin que ello afecte al acceso a su interfaz desde los mencionados territorios. Cuestión bien distinta será cuando el cliente se desplace hasta otro Estado miembro al que el comerciante sí ha dirigido sus actividades, en cuyo caso ha de ser tratado en igualdad de condiciones que el resto de clientes allí domiciliados.

Y con ello, no estaría actuando de forma discriminatoria por motivos relacionados con la nacionalidad o el lugar de residencia o de establecimiento de los consumidores, ya que una cosa es delimitar el mercado de actuación al que dirige su actividad y otra, bien distinta, establecer condiciones de acceso diferentes en esos mercados en función de la nacionalidad o residencia de los destinatarios.

67. En este sentido, si bien es cierto que en el asunto Pammer y Alpenhof el TJUE no juzgó relevante el carácter activo o pasivo de la web del prestador del servicio con el fin de determinar si ha dirigido su actividad hacia el país del domicilio del consumidor ${ }^{108}$, considero que, a tenor de lo dispuesto en el Reglamento sobre bloqueo geográfico, resulta relevante abordar esta materia y reflexionar sobre ella.

Como ya adelanté, la distinción entre webs interactivas y pasivas con el fin de fijar la competencia judicial internacional ya había sido reconocida en la Declaración conjunta del Consejo y la Comisión relativa al artículo 15 del Reglamento 44/2001 que, ciertamente, coincide con la aproximación llevada a cabo por la jurisprudencia norteamericana que ha distinguido entre las páginas web pasivas -que no justifican la atribución de competencia a los tribunales del domicilio del consumidor-y las páginas web interactivas -en cuyo caso el prestador del servicio sí quedaría sometido a los tribunales del foro del domicilio de consumidor- -109 .

68. Para empezar, en una web interactiva podrían concurrir varios de los indicios objetivos señalados por el TJUE en su jurisprudencia con el fin de demostrar el cumplimiento del test de las "actividades dirigidas", mientras que esta cuestión será más discutible cuando se trate de una web pasiva ${ }^{110}$. Cabe sostener, por tanto, el carácter distintivo de las web interactivas - que ofertan y promocionan activamente bienes y servicios en otros Estados miembros promoviendo la contratación on line-, frente a las web pasivas como mero instrumento publicitario que no ofrecen herramientas tecnológicas para realizar pedidos ${ }^{111}$.

${ }^{106}$ Considerando 18 del Reglamwnto sobre bloqueo geográfico.

107 Ibidem, artículo 4.2 .

108 Vid. la Sentencia Pammer y Hotel Alpenhof, en su apartado 79.

${ }^{109}$ Lo que en la jurisprudencia norteamericana se ha denominado "the Pasive versus Active Test". Sentencia del United States District Court for the Western District of Pennsylvania, de 16 de enero de 1997. Caso Zippo Manufacturing Co. v. Zippo Dot Com, Inc., 952 F. Supp. 1119 (W.D. Pa. 1997), disponible en http://apps.americanbar.org/litigation/litigationnews/top_stories/docs/zippo.pdf. Vid., al respecto, R. LAfuente SÁnCHEZ, "El criterio del International Stream-of-Commerce...", loc. cit., p. 185; y Z. S. TANG, Consumer Contracts and the Internet in EU Private international law, en A. SAVIN, J. TrZASKOwSKI (ed.) Research Handbook on EU Internet Law, Cheltenham, Edward Elgar, 2014, pp. 10-11.

${ }^{110}$ Cfr. las Conclusiones de la Abogado General, Sra. Trstenjak, en la Sentencia Pammer y Hotel Alpenhof, apartado 76, quien considera que es posible dirigir las actividades a través de sitios Internet tanto interactivos como pasivos. En relación a la distinción entre $w e b$ activas y pasivas, y sus efectos al objeto de justificar que el vendedor ha dirigido su actividad al domicilio del consumidor, Vid., R. LAFuente SÁnCHEZ, "El criterio del "Internacional Stream-of-Commerce ...”, loc. cit., pp. 194-196.

${ }^{111}$ Como bien señala la Abogado General, Sra. Trstenjak, citando, entre otros, a L. E. GiLlies, "Jurisdiction for Consumer Contracts”, Computer Law \& Security Report, nº 6/2001, p. 397: “... los sitios Internet interactivos permiten la celebración directa del contrato a través de la página web, mientras que los sitios pasivos no lo permiten”. Vid. al respecto, el apartado 61 
Esta materia, no obstante, ha sido objeto de un interesante debate doctrinal y algunos autores han criticado la distinción entre web interactivas y pasivas, bien sea por la dificultad que presenta la clasificación de las webs en distintas categorías ${ }^{112}$; por considerar que una web accesible en el Estado del domicilio del consumidor permite la comunicación y contratación con su titular y hace superflua esta distinción ${ }^{113}$; o porque los consumidores pueden contratar por otros medios diferentes a la propia página web, como el teléfono o el correo postal ${ }^{114}$.

\section{A) Carácter distintivo de las páginas web interactivas y pasivas}

69. Cuando la interfaz en línea del comerciante esté diseñada de forma específica para facilitar información sobre sus productos o servicios y la contratación de los mismos, habrá que entender que está dirigiendo de forma intencionada sus actividades en el sentido de lo dispuesto en los Reglamentos Bruselas I bis y Roma I.

Empero, no basta con el hecho de que el cliente pueda interactuar con el comerciante a través de su interfaz sino que lo relevante será su voluntad de dirigir sus actividades hacia el país del domicilio del consumidor ${ }^{115}$, y para acreditar este extremo habrá examinar qué indicios de los identificados por el TJUE en su doctrina concurren en cada caso concreto $^{116}$, entre ellos:

70. i) las contrataciones realizadas con anterioridad a través de la interfaz en línea con clientes domiciliados en un determinado Estado, lo que pondría de manifiesto el carácter internacional del comerciante o prestador de servicios. De este modo, la existencia de una cartera internacional de clientes domiciliados en otros Estados miembros con los que el comerciante ha contratado electrónicamente y a los que ha ofrecido sus productos y servicios podría ser un signo evidente de su voluntad de dirigir su actividad a esos Estados, salvo que se trate de contrataciones aisladas o que fuesen consecuencia de la voluntad de los clientes extranjeros (consumidores activos) que han decidido contratar a través de la web del comerciante aun cuando su actividad no fuese dirigida al Estado miembro de su domicilio ${ }^{117}$.

71. ii) la lengua utilizada en la configuración de la interfaz, es decir, el uso de una lengua diferente a la habitualmente empleada en el Estado miembro en el que se encuentra establecido el comerciante, por ejemplo, una lengua oficial en el Estado miembro de acogida, si bien es cierto que en la Unión Europea existen países con un idioma común. Por consiguiente, cuando el comerciante se haya tomado la molestia de traducir su interfaz y el consumidor tenga acceso a la información en una lengua accesible al mismo diferente a la original, estaríamos ante un signo evidente de que ha dirigido sus actividades a esos mercados y de su voluntad de contratar con los consumidores allí establecidos.

Significativo resulta el caso de aquellas webs que contengan un link a otra página redactada en un idioma diferente. De ser así, es posible afirmar que el prestador de servicios también desea dirigir su oferta a los países donde ese idioma es oficial. Igualmente, cuando una web se encuentre redactada, además de otros idiomas, en inglés, por ser esta una lengua ampliamente utilizada especialmente en el

de las Conclusiones en el Asunto Pammer y Hotel Alpenhof. En el mismo sentido, A. JAROsZEK, "European online marketplace New measures for consumer protection against old conflict of law rules", Masaryk University Journal of Law and Technology, vol. 9:1, 2015, p. 25.

112 Z. S. TANG, Electronic Consumer Contracts in the Conflict of Laws, Hart Publishing, Oxford, 2009, pp. 112-113.

113 Vid., por todos, G. A. L. Droz y H. Gaudemet-Tallon, "La transformation de la Convention de Bruxelles du 27 septembre 1968 en Règlement du Conseil concernant la compétence judiciaire, la reconnaissance et l'exécution des décisions en matière civile et commerciale", Revue critique de droit international privé, 2001, vol. 90, no 4, p. 639.

114 Vid., P. A. De Miguel Asensio, Derecho privado de Internet, $4^{\text {a }}$ ed., Civitas, Madrid, 2011, p. 967.

115 A. L. Calvo Caravaca y J. Carrascosa González, (Dirs.), Derecho internacional ..., op. cit., pp. 1124.

116 En relación a estos indicios, Vid., por todos, R. LAFUENTE SÁNCHEZ, "El criterio del International Stream-of-Commerce...", loc. cit., p.191-193; y M. Trimble, "The role of geoblocking in the internet legal landscape", IDP, Revista de Intenet, Derecho y Politica, $\mathrm{n}^{\circ}$ 23, diciembre 2016, pp. 48-49.

${ }^{117}$ L. Manigrassi, "Justice, liberté, securité, Arret "Pammer \& Hotel Alpenhof", Revue du Droit de l'Union Européenne, 1/2011, p. 144. 
contexto de internet y las nuevas tecnologías, estaremos ante un signo evidente de la intención del prestador de dirigir su actividad a otros Estados miembros ${ }^{118}$.

72. iii) la posibilidad de utilizar en la contratación a través de la web una moneda diferente a la habitualmente empleada en el país en el que se encuentra establecido el comerciante o prestador de servicios, por ejemplo, la del Estado miembro del domicilio del consumidor. En este caso se pueden distinguir dos supuestos: que la moneda empleada por el comerciante sea exactamente la misma que la de aquellos Estados a los que pretende dirigir su actividad - caso del euro cuando sea utilizado en una interfaz establecida en un Estado de la zona euro para sus relaciones comerciales con el resto de los Estados que forman parte de la zona euro- o que, como estrategia de mercado, se admitan como divisa de pago diferentes monedas extranjeras, en cuyo caso este criterio habrá de evaluarse de forma acumulativa con otros indicios ${ }^{119}$.

73. iv) la inclusión en la web de un número de teléfono de asistencia con indicación del prefijo internacional del Estado miembro del domicilio del consumidor, que pone de manifiesto la voluntad del comerciante de dirigir su actividad a los consumidores domiciliados en otro Estado miembro al facilitarles ese medio de contacto; o

74. v) la utilización de un nombre de dominio de primer nivel del Estado miembro de residencia del consumidor -podría ser "es", "fr", "de"-, que sea distinto al del Estado miembro del comerciante o prestador de servicios, o de un nombre de dominio neutro, como "net", "com", "org".

En principio, cuando una empresa crea un sitio internet con un dominio de primer nivel de un Estado ha de valorarse positivamente su intención de orientar sus actividades a estos mercados con independencia de que pueda dirigirse a los consumidores de otros Estados miembros, y lo mismo ha de entenderse cuando utilice un nombre de dominio neutro. De tal forma que si una empresa domiciliada en Francia crea una interfaz con un dominio "es" habrá que considerar que desea dirigir sus actividades hacia el mercado español pero, al mismo tiempo, también podrá hacerlo hacia otros mercados, por ejemplo, el francés donde se encuentra domiciliada para lo cual será conveniente analizar si concurren además otros indicios ${ }^{120}$.

75. Por el contrario, cuando el comerciante o el prestador de servicios no haya actuado con la finalidad de dirigir sus actividades comerciales o profesionales a los consumidores domiciliados en un Estado miembro a través de su interfaz en línea, podrá afirmarse que se trata de una web pasiva, accesible desde cualquier lugar de la Unión Europea, cuya única finalidad es publicitar sus productos y servicios pero que no revela la voluntad de su titular de dirigir sus actividades a ese Estado salvo que existan otros indicios que así lo demuestren ${ }^{121}$. Al contrario, no acepta la contratación con determinados clientes porque no persigue conquistar los mercados que expresamente está excluyendo de su oferta de servicios ni permite contratar a los consumidores domiciliados en estas jurisdicciones ${ }^{122}$.

${ }^{118}$ La Abogado General, Sra. Trstenjak, considera que en estos casos también han de tomarse en consideración otros criterios. Vid., el apartado 83 de las Conclusiones.

${ }_{119}$ Hay que recordar que en el momento actual varios Estados de la Unión Europea aún no pertenecen a la zona euro, por lo que todavía no han adoptado la moneda única y siguen usando sus monedas nacionales que pueden ser utilizadas en la contratación electrónica. Así, el Reino Unido y Dinamarca en virtud de la cláusula de excepción que negociaron en su día; y Bulgaria, Croacia, Chequia, Hungría, Polonia, Rumania y Suecia por encontrarse en vías de adoptarla. Vid., https://europa.eu/ european-union/about-eu/euro/which-countries-use-euro_es.

${ }^{120}$ S. MARINo, "I contrati di consumo on line e la competenza giurisdizionale in ambito comunitario", Contratto e impresa/ Europa, 1/2011, p. 255. Cfr. N. FABIANO, "E-Commerce e tutela del consumatore: La giurisdizione nei rapporti transfrontalieri", disponible en http://www.studiolegalefabiano.eu/index.php?option=com content\&view=article\&id=76\%3Ae-commercee-tutela-del-consumatore-la-giurisdizione-nei-rapporti-transfrontalieri\&catid=46\%3Acontributi\&Itemid=76\&lang=it, ${ }_{2} \quad$ quien considera que la elección de un nombre de dominio superior no puede constituir una prueba capaz de determinar la voluntad del prestador de dirigir su actividad a un Estado miembro por estar en conflicto con el principio de libertad de empresa en virtud del cual el empresario lo que persigue con un nombre de dominio superior es alcanzar una mayor visibilidad de su empresa.

${ }^{121}$ P. A. De Miguel Asensio, "Social Networking Sites: An overview of applicable law issues", Annali italiani del diritto d'autore, della cultura e dello spettacolo (AIDA), vol, XX, 2011, pp. 13-14.

122 Vid., A. L. Calvo Caravaca y J. Carrascosa González, Conflictos de leyes y conflictos de jurisdicción en internet, Colex, Madrid, 2001, pp. 85-90; y F. EsTEBAN DE LA Rosa, La protección de los consumidores en el mercado interior europeo, Comares, Granada, 2003, pp. 183-184. 
Empero, a tenor de la definición de "interfaz en línea" que facilita el Reglamento, a saber, cualquier tipo de programa informático, incluidos los sitios web y las apps -incluyendo las aplicaciones móviles- que sean utilizadas por un comerciante para dar acceso a los clientes a los productos o servicios del comerciante con el fin de iniciar una operación ${ }^{123}$, surge la duda de si una interfaz pasiva, que persiga un fin meramente publicitario y no permita iniciar una contratación, entraría en el ámbito de aplicación del Reglamento sobre el bloqueo geográfico.

En cualquier caso, hay que recordar que estas situaciones, en las que la web del comerciante persigue un efecto meramente publicitario, no serán muy habituales ya que la interfaz de un comerciante, más allá de su finalidad publicitaria, está pensada y diseñada para captar clientes.

76. En consecuencia, al socaire de la libertad contractual que ampara a los comerciantes podrían distinguirse los siguientes escenarios ${ }^{124}$ :

77. i) Que la página web (pasiva) del comerciante o prestador de servicios persiga una finalidad meramente publicitaria, informando sobre sus productos pero no admitiendo la contratación a través de la misma. En estos casos, en cumplimiento de la obligación que impone el Reglamento sobre bloqueo geográfico, la interfaz ha de ser accesible para los consumidores desde cualquier Estado miembro aunque no permita efectuar pedidos.

78. ii) Que la página web (interactiva) del comerciante o prestador de servicios permita la contratación pero excluya expresamente a los consumidores domiciliados en determinados Estados o jurisdicciones como destinatarios de las actividades ofertadas en su web.

En estos casos no se puede afirmar que el comerciante dirige sus actividades a los Estados o jurisdicciones de los consumidores que ha excluido de una posible contratación ${ }^{125}$. Estas exclusiones pueden referirse a uno o varios Estados y tener un carácter general, es decir, que abarquen todos los productos y servicios ofertados en su web, si bien en otras ocasiones esta limitación podrá afectar únicamente a determinados productos o servicios.

79. iii) Que la página web (interactiva) del comerciante o prestador de servicios se haya elaborado con la finalidad de dirigirse única y exclusivamente a los consumidores de determinados Estados miembros o jurisdicciones. Para ello, podrá crear distintas versiones de su web, con diseño, idioma u otras características específicas diferentes dependiendo de los clientes a los que se dirige. De esta forma, está acotando su mercado de actuación que habrá de tener como límite la ausencia de discriminación por motivos relacionados con la nacionalidad o el lugar de residencia o el de establecimiento del cliente ${ }^{126}$.

Sirva como ejemplo una interfaz que: i) está redactada exclusivamente en español y portugués; ii) especifica los precios solamente para las adquisiciones desde España y Portugal; y iii) menciona que las entregas se efectuarán únicamente en el territorio de la península ibérica y Canarias. En este caso, parece evidente que los mercados a los que está dirigiendo su actividad son España y Portugal.

80. No obstante, cuando un consumidor domiciliado en un Estado al que el comerciante no dirige su actividad contacte con el comerciante a través de la dirección de correo electrónico o del teléfono que aparece en su web solicitando el producto que anuncia y el comerciante acepte su solicitud, en caso de litigio no se vería beneficiado de la protección que proporcionan los Reglamentos Bruselas I bis y Roma I pues queda claro que el comerciante no había dirigido su actividad al Estado del domicilio del consumidor ${ }^{127}$.

${ }^{123}$ Artículo 2, apartado 16 del Reglamento sobre bloqueo geográfico.

124 Vid., al respecto, R. LAfUente SÁnchez , Contratos internacionales electrónicos ..., op. cit., pp. 345-349.

125 B. AÑoveros Terradas, "Restrictions on Jurisdiction Clauses in Consumer Contracts within the European Union" (2003) Oxford U Comparative L Forum 1, at ouclf.iuscomp.org, text afer note 100.

${ }^{126}$ Vid., el documento de la Comisión, "Preguntas y respuestas...", doc. cit., apartado 2.2.5, pp. 19-20.

127 Cfr. A. López-Tarruella Martínez, "El Reglamento 2018/302 sobre bloqueo geográfico injustificado y su relación con el criterio de las actividades dirigidas", Bitácora Millenium DIPr, $\mathrm{n}^{\circ}$ 7, Junio 2018, p. 9, quien considera que el comerciante 
La cuestión será determinar si, la toma de contacto a distancia del consumidor con la página web del comerciante, que el TJUE ha considerado como un indicio a estos efectos, puede bastar o ha de ir acompañado de otros indicios. Según mi parecer, así debería ser, tal y como se puede entrever de la decisión del Tribunal en el asunto Mühlleitner ${ }^{128}$ pues, de lo contrario, no sería defendible la tesis de que el mero acceso a la web del comerciante no implica la acción de "dirigir sus actividades".

81. En definitiva, eliminada la posibilidad de adoptar medidas que restrinjan o impidan técnicamente el acceso a los contenidos de una interfaz en línea a los consumidores de un determinado Estado miembro o área geográfica, los comerciantes que no deseen dirigir sus actividades a esos mercados habrán de adoptar las medidas necesarias para evitar esas contrataciones ${ }^{129}$. Entre estas medidas cabe apuntar las siguientes:

i) la inclusión en la interfaz de disclaimers o cláusulas de exención de responsabilidad que, de forma bien visible y accesible a los consumidores, adviertan acerca de la limitación de su actividad respecto a determinados Estados o mercados y, por ende, a los consumidores domiciliados en los mismos ${ }^{130}$; o que adviertan sobre la limitación a la contratación de determinados productos o servicios ofertados en su web; o del rechazo a la entrega de sus productos en los territorios a los que no dirige su actividad ${ }^{131}$;

ii) la instalación en la web de un sistema de identificación limitado a los mercados con los que el comerciante desea trabajar. De esta forma, se obliga al consumidor a seleccionar el Estado desde el que accede a la misma o en el que han de prestarse los servicios, lo que permitirá al comerciante asegurarse de que está contratando con los consumidores que desea contratar;

iii) la inclusión de un acuerdo atributivo de competencia a los tribunales del domicilio del comerciante o prestador de servicios, siempre que sea posible y se cumplan las condiciones establecidas en el Reglamento Bruselas I bis ya que, de otro modo, esa cláusula de sumisión sería nula ${ }^{132}$. Lo mismo sucederá respecto a los acuerdos de ley aplicable que serán válidos siempre que respeten la protección que proporcionan al consumidor las disposiciones que no pueden excluirse mediante acuerdo a tenor de la ley que sería aplicable a falta de elección ${ }^{133}$.

Con todo ello, el comerciante o prestador de servicios evitaría la exposición a foros extranjeros y a la aplicación de una ley no deseada, puesto que en los contratos celebrados bajo estas condiciones

no puede negarse a celebrar contratos por el hecho de que la residencia habitual del consumidor esté en un Estado miembro al que el comerciante no ha dirigido su actividad, alegando que la ausencia de contratación impediría la aplicación de los artículos 17.1 c) de Bruselas I bis y del artículo 6.1 b) de Roma I.

128 Vid., Sentencia del TJUE, asunto Muhlleitner, cit., apartado 44, donde el TJUE señala que “... el requisito esencial al que se supedita la aplicación del artículo 15, apartado 1, letra c), del Reglamento Bruselas I es el relacionado con la actividad comercial o profesional dirigida al Estado del domicilio del consumidor. A este respecto, tanto la toma de contacto a distancia, como ocurre con la controvertida en el litigio principal, como la reserva de un bien o de un servicio a distancia o, a fortiori, la celebración de un contrato de consumo a distancia son indicios de vinculación del contrato a tal actividad".

${ }^{129}$ Adoptando para ello los denominados métodos de "jurisdiccional avoidance" o "ring-fence mechanisms". Vid., Y. FARAH, "Allocation of jurisdiction and the internet in EU law", European Law Review, Vol. 33, No 2, April 2008, pp. 265-266.

${ }^{130}$ Un buen ejemplo de este tipo de cláusulas o disclaimers, donde se especifican claramente los mercados o destinatarios de los productos, puede encontrarse en las páginas web de los prestadores de servicios financieros y, en concreto, de las entidades comercializadoras o las sociedades de gestión de fondos de inversión. Vid., al respecto, R. Lafuente SÁnchez, Contratos internacionales electrónicos ..., op. cit., pp. 345-349.

131 Z. S. TANG, Consumer Contracts and the Internet..., loc. Cit., p. 12.

${ }^{132}$ Artículo 19 del Reglamento Bruselas I bis. Estas condiciones son las siguientes : que el pacto sea posterior al nacimineot del litigio y que permita al consumidor demandar ante órganos jurisdiccionales distintos de los indicados en el Reglamento o que el pacto celebrado cuando ambas partes tengan su domicilio o residencia habitual en el mismo Estado miembro, atribuya competencia a los tribuinales de ese Estado miembro a no ser que la ley de ese Estado prohiba tales acuerdos. En la doctrina, Vid., E. Álvarez Armas y M. Dechamps, "La direction de l'activité comme critère déterminant la protection juridictionnelle des consommateurs dans l'e-commerce européen (commentaire de l'arrêt Pammer-HôtelAlpenhof)", Revue du Droit des Technologies de l'information, No 44/2011, p. 95; y Y. FARAH, "Allocation of jurisdiction ...", loc. cit., p. 266.

133 Vid., artículo 6, apartados 1 y 2, en relación con el artículo 3 del Reglamento Roma I. 
el consumidor no podrá alegar que el comerciante ha dirigido su actividad al país en el que se encuentra domiciliado con el fin de activar la protección que otorgan los Reglamentos Bruselas I bis y Roma I ${ }^{134}$.

\section{B. Distinción entre consumidores activos y pasivos}

82. Al igual que sucede con la web del comerciante, donde es posible distinguir entre páginas interactivas y pasivas, también se puede diferenciar entre consumidores activos y pasivos dependiendo del rol que asuman en cada momento. Se tratará de un consumidor activo cuando busque la contratación del producto o servicio a través de la web pasiva de la otra parte contratante que, en principio, persigue una finalidad puramente publicitaria o se dirige a mercados en los que no se encuentra domiciliado el consumidor o a destinatarios entre los que no se le incluye; y de un consumidor pasivo cuando el comerciante le dirija sus actividades comerciales o profesionales a través de su web interactiva ${ }^{135}$.

De ahí la importancia que adquiere la distinción entre páginas web interactivas y pasivas a pesar del rechazo que ha mostrado el TJUE a pronunciarse sobre esta materia pues no puede negarse que existe una conexión entre las webs interactivas y los consumidores pasivos y las webs pasivas y los consumidores activos.

83. A partir de ahí, puede afirmarse que la protección que otorgan los Reglamentos Bruselas I bis y Roma I se limita únicamente a los consumidores pasivos, o sea, a aquellos que no se desplazan del país de su residencia habitual para contratar con el comerciante. Ahora bien ¿qué sucede con los consumidores dinámicos o activos que accedan a una interfaz pasiva que, en principio, no dirige sus productos o servicios al país del consumidor?

Hoy en día, no resulta infrecuente que un consumidor contrate a través de una página web pasiva a pesar de que el Estado en el que se encuentra domiciliado haya sido excluido en la web del comerciante, a través de un disclaimer, como mercado de conquista. En esos casos, como ya he señalado, el contrato así concluido no podría considerare amparado por la protección que otorgan las normas de Derecho internacional privado al no cumplirse el requisito de las "actividades dirigidas" al Estado miembro del domicilio del consumidor, salvo que así hubiese sido pactado por las partes ${ }^{136}$, y tampoco sería aplicable la ley del lugar de su residencia habitual. Sin embargo, un sector doctrinal se manifiesta favorable a otorgar al consumidor que contrata a través de internet la misma protección que al consumidor "clásico", es decir, aquel que recibe una oferta a través de catálogo, prensa o televisión, aun cuando la actitud del consumidor que busca a través de internet pueda considerarse una actitud activa ${ }^{137}$.

84. De cualquier modo, entiendo que los límites de esta distinción -consumidor activo y pasivo- son muy difusos debido al fin último que persigue toda página web -la invitación a contratar los productos o servicios que oferta-, y porque en el ámbito de internet esta distinción resulta aún más compleja teniendo en cuenta que el simple hecho de acceder a la interfaz del comerciante convierte

${ }^{134}$ Algunos autores consideran que esta norma ha de ser interpretada como un elemento exigible con el objeto de que el consumidor pueda beneficiarse de la protección que el precepto le otorga -poder demandar ante los tribunales de su domicilio-, y no como un vínculo atributivo de competencia judicial internacional. Vid., al respecto M. Vargas Gómez-URrutia, "Protección internacional de los consumidores ...”, loc. cit., pp. 670-671.

${ }^{135}$ H. Kronke, "Applicable Law in Torts and Contracts in Cyberspace”, en K. Boele-WoelKi and K. Kessedjian, (Ed.) Internet. Which Court decides?, Which Law applies?, Quel tribunal decide?, Quel droit s'applique?, Kluwer Law International, 1998, The Hague, pp. 82-83; y N. Rosner, "Interntional Jurisdiction in European Union E-commerce Contracts", disponible en http://hdl.handle.net/11370/574c2f4f-5662-477f-9181-3a2afba98cd2, p. 5.

${ }^{136}$ F. Debusseré, “ International jurisdiction over E-Consumer contracts in the European Union : Quid Novi Sub Sole ?, International Journal of Law and Information Technology, vol. 10, $\mathrm{n}^{\circ}$ 3, 2002, p. 351.

137 Vid., por todos, G. KAUfMANN-KoHLER, "Internet: mondialisation de la comunication - mondalisation de la résolution des litiges?, en K. Boele-Woelki and K. Kessedjan, (Ed.) Internet. Which Court decides?, Which Law applies?, Quel tribunal decide?, Quel droit s'applique?, Kluwer Law International, 1998, The Hague, pp. 135-140. Cfr. A. L. CAlvo Caravaca y J. Carrascosa GonzÁlez (Dirs.), Derecho Internacional privado vol .II, décimo segunda edición, Granada, Comares, 2011-2012, p. 818, quienes consideran que a pesar de estos disclaimers cuando se produzca la contratación a petición de la otra parte domiciliada en un Estado excluido previamente estaremos en presencia de "actividades dirigidas" (tesis del contrato real) hacia el Estado del consumidor. 
a todo consumidor en "potencialmente activo". Consecuentemente, será necesario analizar cada caso concreto antes de acometer una definición genérica de la figura del consumidor activo en el ámbito de la contratación $B 2 C^{138}$.

Por otra parte, no hay que olvidar que tanto la redacción del artículo $17.1 \mathrm{c}$ ) del Reglamento Bruselas I bis cuanto la del artículo 6.1 b) del Reglamento Roma I difuminan, en parte, la clásica distinción entre consumidor activo-pasivo al eliminar el requisito que caracterizaba la figura del consumidor pasivo, esto es, la realización de los actos necesarios para la celebración del contrato en el Estado donde se encuentra domiciliado, pues esta distinción pierde su razón de ser cuando nos encontramos en presencia de contratos electrónicos ${ }^{139}$.

\section{Relevancia del lugar de entrega de los productos o servicios del comerciante para determinar si ha dirigido sus actividades al Estado del domicilio del consumidor}

85. Este Reglamento permite a los comerciantes designar o acordar con los clientes el cliente el lugar del Estado miembro en el que ofrece sus servicios de entrega. En la práctica, esto significa que no le obliga a realizar entregas transfronterizas de productos en otros Estados miembros o fuera de los territorios designados al efecto. Las opciones de entrega, por lo tanto, son una elección comercial sujeta a la voluntad del comerciante que podrá abarcar todo el territorio de la Unión, uno o varios Estados o, simplemente, el Estado miembro de origen del comerciante ${ }^{140}$.

Las condiciones de entrega, determinadas por el comerciante o pactadas con el cliente, han de estar especificadas claramente en las condiciones generales de acceso y en ningún caso podrán discriminar a los clientes por razón de su nacionalidad, lugar de residencia o lugar de establecimiento ${ }^{141}$. Y, en consonancia con lo dispuesto en la Directiva sobre los derechos de los consumidores ${ }^{142}$, el comerciante esta obligado a facilitar a los clientes en su interfaz la información precontractual clara y precisa sobre los procedimientos y condiciones de entrega -zona geográfica en la que ofrece su servicio de entrega, Estados en los que no lleva a cabo ese servicio, costes de entrega, transporte, envío o manipulación, cargos adicionales...- ${ }^{143}$.

86. A mi entender, la exclusión de un territorio determinado del ámbito geográfico en el que el comerciante realiza los servicios de entrega, podría ser interpretada como un indicio -negativo, en este caso-, pero no determinante, de que no ha dirigido sus actividades a esos mercados, pues podrían concurrir otros indicios que así lo acrediten, como el hecho de que el consumidor hubiese concluido el contrato a través de la interfaz del comerciante y desde el Estado miembro de su domicilio o residencia habitual.

En cualquier caso, no hay que olvidar que el hecho de que sea el consumidor el que se desplace para recoger el producto a otro Estado miembro no tendría relevancia a estos efectos a tenor de la doctrina del TJUE que, hasta la fecha, únicamente ha considerado la conducta del comerciante, y no la del consumidor, con el fin de aplicar el régimen especial de protección en materia de contratos de consumo ${ }^{144}$.

87. En consecuencia, cuando el comerciante excluya la entrega de sus mercancías en algunos Estados miembros o a los consumidores domiciliados en un determinado territorio, y estos decidan contratar con el comerciante aun a sabiendas de que este no le ofrece la posibilidad de entregarle el producto

\footnotetext{
138 Vid., F. Debusseré, "International jurisdiction over E-Consumer ...”, loc. cit,. pp. 352-353.

139 Vid., P. CACHIA, "Consumer contracts in European private internacional law: The sphere of operation of the consumer contract rules in the Brussels I and Rome I Regulation», European Law Review, vol. 34, n 3, June 2009, pp. 489-490.

${ }^{140}$ Vid., el Considerando 28 del Reglamento sobre bloqueo geográfico.

${ }^{141}$ Ibidem, artículo 4.1 a) y Considerando 23.

${ }_{142}$ Vid., artículos 5, 6 y 8 de la Directiva 2011/83/UE del Parlamento Europeo y del Consejo, de 25 de octubre de 2011 sobre los derechos de los consumidores, por la que se modifican la Directiva 93/13/CEE del Consejo y la Directiva 1999/44/CE del Parlamento Europeo y del Consejo y se derogan la Directiva 85/577/CEE del Consejo y la Directiva 97/7/CE del Parlamento Europeo y del Consejo (DOUE L 304, de 22.11.2011).

${ }^{143}$ Vid., el documento de la Comisión, "Preguntas y respuestas...", doc. cit., apartados 2.3.6 y 4.1.4, pp. 23 y 42.

144 J. I. PARedes Pérez, “Medidas contra el bloqueo geográfico injustificado...”, loc. cit., pp. 17-18.
} 
en el territorio en el que tienen su domicilio o residencia habitual, tendrán que organizar con sus propios medios la recogida en el lugar donde el comerciante ofrezca servicios de entrega.

En estos supuestos, nos encontraremos en presencia del "consumidor móvil" tal y como algunos autores lo han definido ${ }^{145}$, y su protección quedará incluida en el ámbito de aplicación de las normas previstas en los artículos 17.1 c) del Reglamento Bruselas I bis y 6.1 b) del Reglamento Roma I únicamente cuando, mediante el cumplimiento de otros indicios, pueda acreditarse que el comerciante ha dirigido su actividad al Estado miembro del domicilio del consumidor aunque, posteriormente, este haya tenido que desplazarse a otro lugar con la finalidad de recoger el producto o servicio objeto de la transacción, tal y como ha señalado el TJUE en su doctrina ${ }^{146}$.

No será así cuando no se cumpla el requisito de la actividad dirigida al Estado miembro del domicilio del consumidor y este haya contratado a traves de la web de otro Estado miembro y posteriormente se desplace a recoger el producto en el territorio de este último Estado.

88. Sensu contrario, podría entenderse que el comerciante ha dirigido sus actividades al Estado miembro del domicilio del consumidor en los siguientes supuestos:

i) De un lado, cuando su interfaz incluya asistencia a los consumidores domiciliados en un determinado Estado para que organicen la recogida del producto, por ejemplo, poniendo un teléfono a su disposición o respondiendo los mensajes de email en su propio idioma; o cuando la mencionada interfaz esté redactada en el idioma del país de destino o se incluya una herramienta de traducción automática.

ii) De otro lado, cuando el comerciante incluya en las condiciones generales de acceso, o en la información precontractual en su web, o a través de email, que se encargará directamente del envío y entrega de las mercancias en el país donde tiene su residencia habitual el consumidor; o cuando incluya las opciones que tiene el consumidor para recibir en su domicilio la entrega de las mercancías; o cuando incluya la web de la empresa que va a gestionar la entrega de la mercancia; o simplemente un link a la web de la empresa encargada de gestionar la entrega.

89. Sin lugar a dudas, el Reglamento exige una actitud activa del comerciante o prestador de servicios, que vaya más allá de la mera eliminación del bloqueo geográfico, a la hora de regular los servicios de entrega de los productos que comercializa a través de su interfaz en línea. Para ello, en el marco de las condiciones generales de acceso o en el acuerdo con el cliente facilitará los datos para la recogida, pudiendo incluir en su interfaz la mención de números de teléfono con indicación del prefijo internacional, traduciendo su web al idioma habitualmente empleado en el Estado del domicilio del consumidor, o prestando su apoyo para la entrega de las mercancias o servicios mediante la descripción de itinerarios para llegar desde otros Estados miembros hasta el lugar de establecimiento del comerciante, ya sea por carretera, ferrocarril o transporte aéreo, cuando sea ese el lugar de entrega de la mercancia. En los casos anteriores, se pueden reconocer claramente algunos indicios coincidentes con los ya identificados por el Tribunal de Justicia en su sentencia Pammer y Alpenhof para considerar el criterio de las "actividades dirigidas".

A mi parecer, cuando el Reglamento se refiere a las opciones de entrega por el comerciante esta pensando en las ventas activas propias de las web interactivas que permiten identificar los mercados a los que el comerciante ha dirigido sus actividades, especialmente cuando, en el marco de la relación contractual, decide asistir al consumidor para que este pueda recibir la mercancia o servicio contratado electrónicamente en el país en el que tiene su domicilio o residencia habitual.

145 Vid., T. Ballarino, "Dalla Convenzione di Roma al Regolamento Roma I", Rivista de Diritto Internazionale, vol. 1, 2009, p. 50; L. E. GILLIES, "Choice of law rules for electronic consumer contracts: replacement of the Rome Convention by the Rome I Regulation", Journal of Private International Law, v. 3, 2007, p. 89; y G. PASSARELLI, "The Protection of the European Consumer in Private International Law. Some General Remarks, Contratto e impresa / Europa, no 1, Giugno 2014, pp. $210-211$.

146 Vid., Sentencia del TJUE, asunto Muhlleitner, cit., apartado 44. 


\section{El cumplimiento de los requisitos legales nacionales no contractuales del Estado miembro del cliente y su incidencia en el criterio de las "actividades dirigidas"}

90. Como ya adelanté, la observancia del Reglamento sobre bloqueo geográfico y, en particular, la no aplicación de condiciones generales de acceso diferentes a los productos del comerciante, no implica que éste venga obligado a cumplir con los requisitos legales nacionales no contractuales relacionados con los productos y servicios respectivos del Estado miembro del cliente, o a informar a los clientes sobre esos requisitos ${ }^{147}$. Al referirse a estos requisitos legales, el Reglamento está pensando en aquellos que no se derivan de la relación contractual entre el cliente y el comerciante y que resultan de aplicación de conformidad con la legislación aplicable en el Estado miembro del cliente. A título de ejemplo, pueden mencionarse los relacionados con el etiquetado de los productos que se comercialicen o con aspectos sectoriales, en definitiva, normas que buscan la protección del consumidor ${ }^{148}$.

91. De esta manera, las diferencias existentes entre las legislaciones nacionales de los Estados miembros, tanto en materia de protección del consumidor cuanto en lo que atañe a la regulación de los comerciantes y su actividad, pueden constituir un motivo justificado para que ciertos profesionales decidan no desarrollar su actividad en una parte del mercado único digital y rechacen vender o prestar servicios a los consumidores domiciliados en esos Estados miembros, sin que ello sea óbice para que los consumidores establecidos en cualquer Estado miembro puedan acceder a su interfaz en consonancia con lo dispuesto en el Reglamento sobre bloqueo geográfico.

92. Por el contrario, el cumplimiento de esos requisitos nacionales no contractuales no podrá orillarse cuando el comerciante haya dirigido sus actividades a un determinado mercado y contrate con los clientes allí domiciliados. Dicho de otro modo, ese comerciante viene obligado a cumplir con la legislación nacional a la que está sujeto por el hecho de operar en ese determinado Estado y, en particular, en materia de protección del consumidor, mientras que su exclusión quedaría totalmente justificada cuando se trate de Estados a los que no ha dirigido su actividad ${ }^{149}$.

Por consiguiente, el respeto a la legislación nacional del Estado miembro del domicilio del consumidor podría considerarse como una prueba fehaciente de que el comerciante ha dirigido su actividad a ese territorio, si bien es cierto que hasta la fecha la doctrina del TJUE no ha incluido este elemento entre sus indicios para justificar el test de las "actividades dirigidas".

\section{5. ¿Cómo ha de interpretarse el hecho de que del Reglamento no conlleva para el comerciante ningún coste adicional asociado a la competencia judicial o a diferencias en el derecho aplicable?}

93. El Reglamento, en sus considerandos, trata de aportar alguna luz sobre esta cuestión al distinguir entre los comerciantes que no ejercen o dirigen sus actividades al Estado miembro del consumidor y los que sí lo hacen. En el primer supuesto, dispone que el cumplimiento del Reglamento no conlleva para el comerciante ningún coste adicional asociado a la competencia judicial o a diferencias en el derecho aplicable, mientras que en el segundo la voluntad del comerciante de dirigir sus actividades hacia un mercado concreto y su intención de contratar con los consumidores allí domiciliados ha quedado patente, por lo que ha podido tener en cuenta tales costes ${ }^{150}$.

94. En mi opinión, esto no introduce cambios sustanciales en la operativa que hasta la entrada en vigor del Reglamento han venido aplicando los comerciantes y prestadores de servicios. De tal suerte que cuando un comerciante no deseaba dirigir sus actividades a un determinado Estado podía utilizar la técnica del bloqueo geográfico o incluir un disclaimer en su página web, manifestando, de este modo, su voluntad de evitar la contratación con esos clientes. Y para ello, antes de adoptar esa decisión había

\footnotetext{
${ }^{147}$ Vid., los artículos 4.1 a) y 4.3 y el Considerando 29 del Reglamento sobre bloqueo geográfico.

148 Vid., el documento de la Comisión, "Preguntas y respuestas...", doc. cit., apartado 2.3.14, p.26.

${ }^{149}$ Ibidem, apartados 2.3 .21 y 2.3 .22 , pp. 28 y 29.

150 Vid., el Considerando 26 del Reglamento sobre el bloqueo geográfico.
} 
analizado los riesgos que implicaba dirigir su actividad a ese mercado, tanto los costes económicos de comercializar y entregar sus productos en dicho territorio cuanto los costes jurídicos que implicaría tener que litigar ante los tribunales del domicilio del consumidor y aplicar la ley de ese Estado.

En definitiva, tal y como sostiene el Reglamento, su aplicación no debe suponer ningún coste adicional asociado a la competencia judicial o a diferencias en el Derecho aplicable para aquellos comerciantes que vayan a seguir actuando como hasta ahora lo han hecho, y que tienen preparada su interfaz para excluir de su actividad aquellos clientes a los que no deseen dirigir sus actividades por el coste económico o jurídico que ello pueda representar. Como ya he señalado, el hecho de eliminar el bloqueo geográfico injustificado no implica que los comerciantes tengan que ampliar el ámbito territorial en el que hasta ahora han venido desarrollando su actividad.

\section{Consideraciones finales}

95. La contratación on line ha venido funcionado desde hace ya algunas décadas con diferentes resultados, dependiendo del perfil de consumidor existente en cada país y de los mercados elegidos por las empresas y prestadores de servicios para desarrollar su actividad. Si bien la experiencia existente en esta materia puede considerarse positiva, no hay que olvidar los obstáculos que todavía subsisten para conseguir un verdadero mercado único digital en la Unión Europea. Uno de ellos, el bloqueo geográfico que permitía a los comerciantes discriminar a la hora de comercializar sus productos en función de la nacionalidad, del lugar de residencia o establecimeinto de los consumidores, ha sido eliminado a raiz de la reciente entrada en vigor del Reglamento sobre bloqueo geográfico.

96. Por otra parte, resulta un hecho cierto que cuanto mayor sea el número de transacciones que se efectuen por vía electrónica, mayor será el número de conflictos que puedan surgir entre las partes. En estos casos, en el ámbito de la contratación $B 2 C$, entran en juego las normas de Derecho internacional privado y, en particular, las relativas a la protección del consumidor previstas en los Reglamentos Bruselas I bis y Roma I, con el fin de determinar la competencia judicial internacional y la ley aplicable en función de la actividad dirigida por los comerciantas al Estado del domicilio o residencia habitual del consumidor.

Para aplicar apropiadamente las mismas, la jurisprudencia del TJUE interpretando estas normas debería ser suficiente. Sin embargo, ello no impedirá que las particularidades de cada caso puedan plantear nuevos problemas a la hora de determinar el tribunal competente y la ley aplicable a los contratos de consumo electrónicos celebrados en el ámbito del Mercado Único Digital Europeo.

97. Como he puesto de manifiesto, la jurisprudencia del TJUE protege de forma clara a la parte más débil en la relación contractual pues la interpretación de la expresión "dirigir las actividades" al Estado miembro del domicilio o residencia habitual del consumidor que ha llevado a cabo adquiere una dimensión muy amplia que puede o no coincidir con la voluntad real del comerciante o prestador del servicio. Esta afirmación tiene su fundamento en el amplio catálogo de indicios (sin carácter exhaustivo, por lo que podrían ampliarse en un futuro) que ha elaborado el TJUE para justificar que un comerciante (o su web) tiene la voluntad de dirigir su actividad hacia el Estado del domicilio del consumidor, si bien es cierto que habrá que evaluar y graduar en cada caso concreto la concurrencia de uno o varios de estos indicios.

En mi opinión, si bien el consumidor representa la parte más débil en la relación contractual, y como tal ha de ser objeto de protección, no se trata de ahondar en el desequilibrio entre las partes desde la perspectiva del comerciante, sino que habrá que analizar en cada caso concreto tanto los indicios que concurran en su página web cuanto las medidas activas que haya adoptado para dirigir su actividad al mercado de conquista o, a sensu contrario, las medidas adoptadas para evitar las relaciones con el foro del consumidor con el fin de no verse demandado ante sus tribunales y sometido a la ley de ese Estado. Pues una protección exorbitante del consumidor podría romper el equilibrio que ha de existir entre el interés del Estado - la protección de sus ciudadanos designando competentes sus tribunales- y el de los comerciantes y prestadores de servicios que se ven sometidos a los tribunales del demandante y a la ley de su Estado. 
Por esa razón, entiendo que las condiciones que impone el TJUE en su doctrina respetan el deseable equilibrio que ha de existir entre las partes y resultan perfectamente compatible con el derecho a la tutela judicial efectiva sin que pueda plantearse una posible indefensión por ninguna de las partes.

98. En este contexto, considerar que el Reglamento sobre bloqueo geográfico injustificado implica que el comerciante ha dirigido su actividad a todo el territorio desde el que su web sea accesible, sería abundar en esa interpretación generosa que el Tribunal ya ha acuñado favoreciendo aún más la protección del consumidor. Por ese motivo, el propio Reglamento ser apresura a rechazar tal interpretación.

Y así, tal y como he señalado a lo largo de este trabajo, la aplicación del Reglamento sobre bloqueo geográfico es compatible con la aplicación de las normas de Derecho internacional privado previstas en el artículo 17.1 c) del Reglamento Bruselas I y el artículo 6.1 b) del Reglamento Roma I en materia de contratos de consumo.

Del mismo modo, la distinción entre el acceso a la interfaz del comerciante y la acción de dirigir sus actividades comerciales al Estado miembro del domicilio o residencia habitual del consumidor ha quedado claramente expuesta.

99. Por consiguiente, los criterios identificados por el TJUE en su jurisprudencia siguen manteniendo su vigencia y a ellos habrá que acudir para determinar si el comerciante ha dirigido o no su actividad al Estado miembro del consumidor al objeto de que este pueda activar la protección que le otorgan los Reglamentos Bruselas I bis y Roma I.

$\mathrm{Y}$, en este sentido, considero que no resulta necesaria una reinterpretación ni modificación de esos criterios sino más bien una adaptación de los mismos a la nueva situación planteada tras la entrada en vigor del Reglamento sobre bloqueo geográfico. Todo ello, sin perjuicio de la consideración de otros elementos que incorpora el mencionado Reglamento, que también pueden tener incidencia a la hora de considerar hacia donde ha dirigido el comerciante su actividad, por lo que no es descartable que en un futuro no muy lejano el TJUE tenga que afrontar de nuevo esta cuestión y pronunciarse sobre los criterios previstos en el Reglamento sobre el bloqueo geográfico, ampliando así el listado no exhaustivo de indicios que hasta ahora ha aportado o, en su caso, aclarando o redefiniendo los ya existentes.

100. Concluyendo, pues, podría afirmarse: i) que la aplicación del Reglamento sobre bloqueo geográfico no interfiere en la interpretación y aplicación de los indicios definidos por el TJUE respecto al concepto de "actividad dirigida" al Estado miembro del consumidor; ii) que esos criterios siguen plenamente vigentes en el marco de la actividad regulada por el Reglamento sobre bloqueo geográfico; y iii) que al socaire de la aplicación del mencionado Reglamento y de la observancia por parte de los comerciantes de la prohibición de las prácticas de bloqueo injustificado que regula, podrían inferirse otros indicios compatibles con los ya definidos por el TJUE con el fin de identificar si un comerciante ha "dirigido su actividad" al Estado miembro del consumidor; indicios que, en cualquier caso, habrán de ser refrendados o rechazados por el TJUE en su futura jurisprudencia. 